



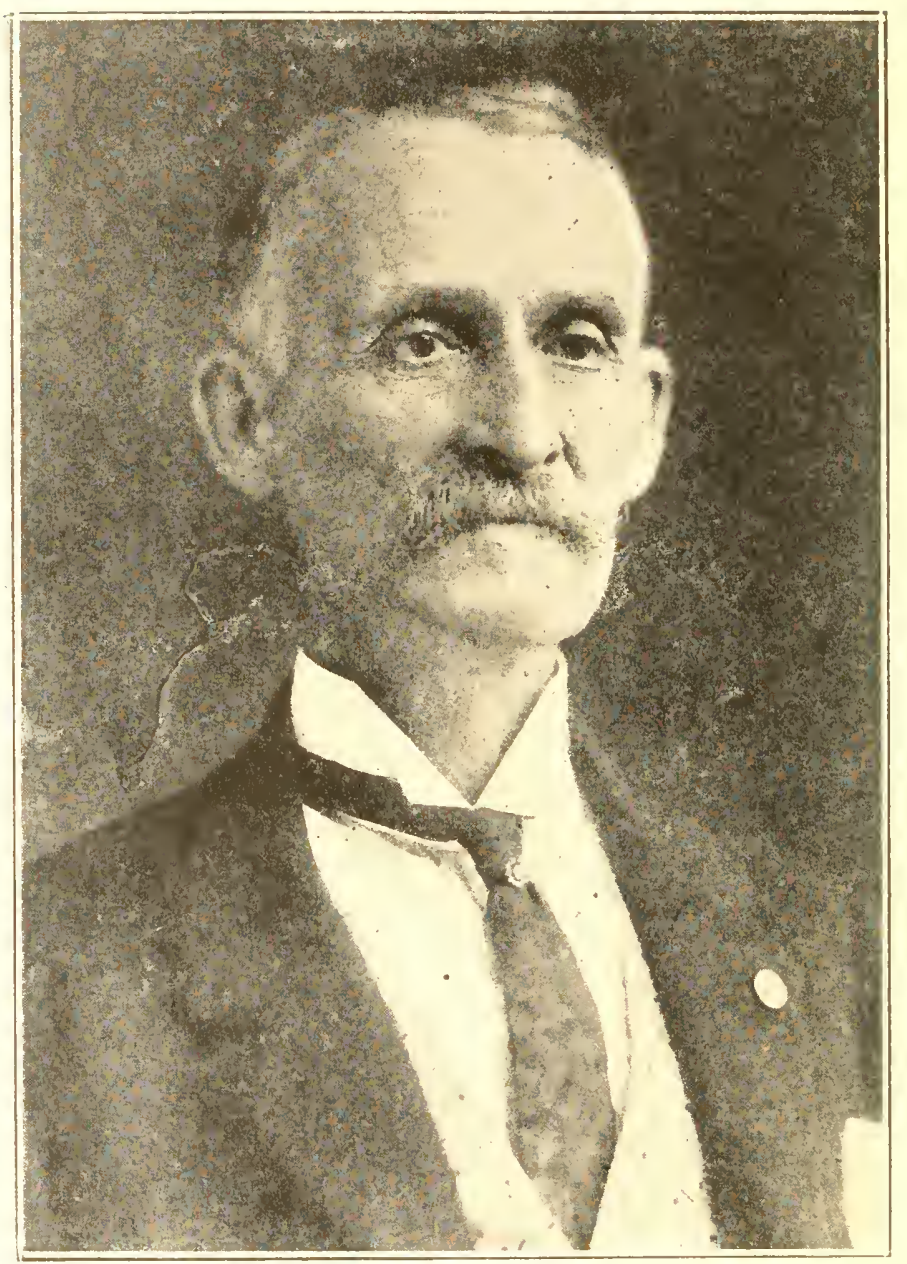

N. J. MCARTHUR 


\title{
PEN PICTURES
}

-OF-

\section{Standard Cotton Grades}

\author{
DESIGNED
}

For Use as a Text Book in the Common Schools of the

COTTON BELT

Combined with

"THE COTTON GRADER"

By N. J. ICARTHUR.

Copyrighted Cctober 1910 
Copies of this work an Cintun liralling will not be sold to thuse who may nese them. They will be leased only and witl remain the property of the Author, subject to be returned an demand. The term of lease, howerer, will be imlefinite, regulated wholly by a compliance of the lessee with the terms of lease. These terms will be set forth in a contract and if they are not allused the bouk will remain in the pressession of the lessce without linit of time. See Waming lage 96. 


\section{INTRODUCTORY.}

In Nay. 1908. I published the ". Cittum Lirader." intendings it to be a full and complete text wn the subjeet of (inton Gradling. Later I prepared and pulplished the same matter in more elalurate form and detail. and made it supplenental to



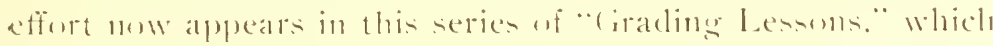
I entecive tu be the most comprelsensive and yet the simplent and clearest presentation of the sulpject to be affered. Anticipating the proseresive illea which will inevitably introcluce this topie inte the curriculum of ent commonem sclemels. these lessons have been prepared in the best form forr a text work an the subject. I full therretical kimwlerlge of the yuestion maly be alined ly a careful study of the Pen Pictures purtrayed. In this pretrayal, imaginary types are so vividly drawn, that the original Real may be easily kmown on sight. lint with a set of Real samplen in hand, the whole subject is placed within easy mental aratsp. These samples are of mere

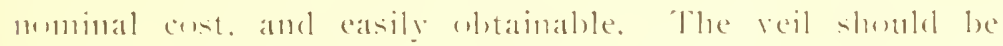
lifterl. The manifest truth should be proclamed that the mesterious intricacies of cotton manipulations log the commmercial worlel have monecessatily heen made to incluele the simple preseses of gralling or "salying what it is." while it is in the hands of the prenducer.

With the hope that it will accomplish ereat soust the work is most respectfully stbmitted by

The Itithre. 



\section{PREFATORY}

\section{An Appeal to Southern Patriotism.}

A man has been robbed of one humbled dollars. You reat of the incident with a sort of indifferent sympathy for the sufferer. The robluer and his victim, as yom sulposes are luth nuknown to you, The money was not yours. The puer robber perhaps needed it. Later you learn that the viction was your debtor,- that he was hearing this, his omly momey, w yout to cancel that delet. How changed mus the view you talie of the matter! Your indifferent sympatly hecomes intense interest. The pour roblere is mow a vile wretch, and the whole ciremmstance beenmes a matter demanding your persomal attention

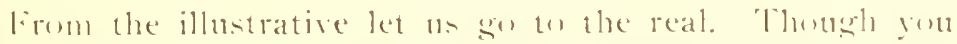
may live in a cotton sitate in which as many as two million bales of cottum are anmually prolucerl and marketed, if you are mot a farmer. You may argue that it is a matter of mo contcern to gon what money or price this cotton may bring its producer. lint led us suppose that these producers by a guestionable system of grading have been made to lose at least one cent a pound or five dollars per bale on every bale suld. This means ten millions of follars entirely remoned from the money wealth, or as it is termed, the mume ciremlation of ym state. Let the term. circulation, apply in its fullest sense to the returns of your own business or profession, and let the sitate. which is ever rour first deloter. be thus held up aml robleed of the one humdred dollars. more or less. she may he learing to yout. What of the incielent?

Three-fifths of the entire crop of all the states in suld by "advancing" comntry merehants. who know mothing wf cotton srading, and with an apology to an excepted few, who care less. Account Closing is the paramomnt object attemling all sales. A hasty settlement of all acennts must be made. The impatience of the Farmer Landlord, resident on farm ur not. is no less than that wif the merchant. He stands by tuget hic 


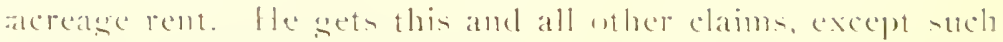
at he kindheatedly "extends" his tenants to maintain "obligatory relations." He is perfecetly satisfied thomels thomsands wi home-helomging dollats may hase been taken away in this closing of acommts. The indeprendent mall farmer is mo wiser. He is told lug the resident or risiting expert that his

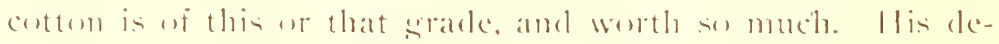

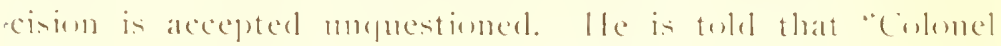
Lamblherl has sold torlay the same cothem at that figure." lle lets his wo. and gerhaps. with each sale, he has let we from three to ten dollars that he might have retamed in his own

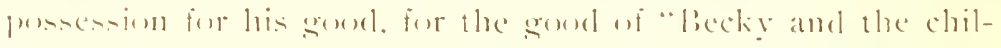
dren." and for the bigher hubldiug of the corculating wealth of his commomity. He dees mot kmow. He has been tamght that he cammot mentally penetrate tle mosolvalsle mysteries of cottun warling. Is it met written that to him it must he like



I sal these thimgs mone to cite the fate that the comblition is

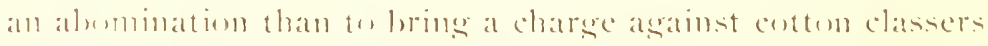

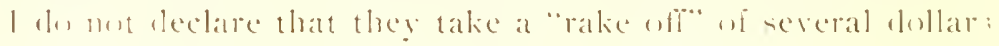

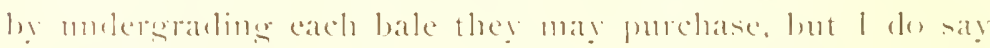
"Plue calp is lown." They can do it. Is lusinese ment they are in their line for husinesis. and an a clan. they mal be rated amazingly human.

ln formulating the predieate of this appeal it wate mot my

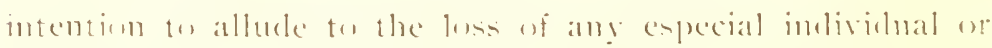
clase. lont I will refer again to the sereral parties named at participants in acenunt elosing and selling day transatetions, ancl leate deduetions to the publie that onght to be vitally in-

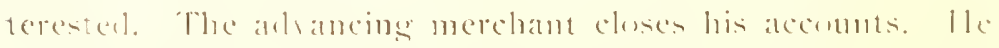
is reatly to pick up a few crippled cash dollars that may stagger his way. but als our colored linguists would sa! " "Nust-


next (rep). He in satisfied. The lambllord farmer has had

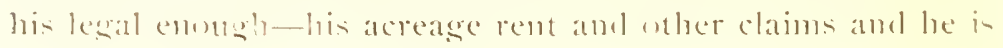


satisfied. Whe tenant farmer, the phw pusher, expected nothing and has received it. He accepts his few dollars. "obligatory" money and the clean cleared anmal family acquisition of a new baby as all sufficient wroumels for mortal contentment. He retums to his home-that typical hothed of a clebacel and legenerate Southern citizenship. gloriously satisfied. Mll resident ministers, lawers, doctors. schoul teachers and other business men-including the bankers-who speak proudly of having "moved the crop," - have been blind to the acorrence. They have seen mo money wh that shomld have remained at home. The me hundred dollars each, more or less, that would have been due them by the sitate, and prompty paill, has been canceled by a counter entry of "rublic innerance."

Is there a fuestion as to where this money goes? I will answer that mot one dollar in ten thousand of "cotton profit money" is circulated by direct resular depustims or reinvesting in any section wi the cotton territury, moless perhaps it is the tip of reward given to the Fopert field ciraler, for combining with that puatification the character of faithful ans obedient servant. Resident loblers of entton mill stock also may be excepted, hut it will be fomd that the weater number of un buated home owned eotton mils are operated hy the appital uf num-residents. Apply this system to the whole cottom section, let it extend back orer at period of ten years. and reduce the pereentage of loss to a minimum fignre. it would still reach the curmons sum of Two Hundred and lifty Millons of lollars. This hose is sustained by all the perple of the entton Sitates, as primary and secondary suffererers, in the oreler I lave set fortl. Vet we, all uf us, like the hilarious, ismorant tenant farmer, are satisfied. I was born and reared in the south in the land of entons. I am proud of it. but I do mot know why. saving the fact that it makes me a democrat-whatever that may he. No. I am proud of nuy people-of our olden customs, and of all which 
it has been whe pricle to boast. I know we are not slow-minded:

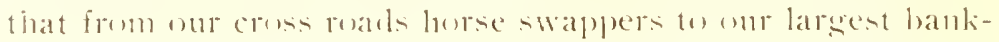
ers. merehants, and mannfactmers we have momey chasers and money getters of the shrewdent "dollat pere cent." type. lint cottom, what of eottom? Though it is the bigerest known commmercial propustion-the areatest simgle momey bearing promwet in the whole worlel, and thengh we of the south have a momopoly of monership, we have hitherto ingored all someres of loss, only lowking with trembling ansiety to the settling we onr domestic acommts and making an anmul balance of wn

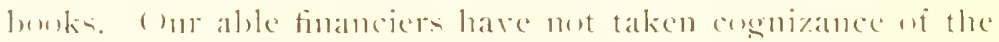
lose that may and therefure does exist as a result wi mulersrading, and strange to say, they have never manifested interest emongh in the mater to look for that or any wher mones

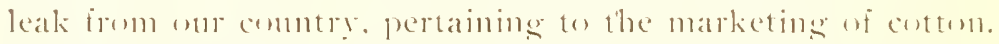
cimsideration of this quention has been left to the produces. Who in the problucer? lect us loxk for him. It is mest the landmoner. Who is satisfied with preserved bands and collected rents. though from his loroad acred fomain humdreds of hales may wo to market. It is mot the small independent wower. For themph he sits in council with his fellus amel adopts high-sennding resolutions. he feels "mimerity sensations." He kmews that a majorits of his fellows are like the tenant, lonnd to the adrancing merchath. He feels helpless-he is helpless. and he knows that his high sombling reselutions are absolutely worthless exeept for the puetic bealuty uf their composition. The temant farmer is mot the problueer. for he is but a eres in the eneneral mechanism. Neither is the arluancing merchant. Prue the landlord has waived his risht to do something directly to this hand of tenant plow pusthers. He stepe aside and rields this right to the alvaneing merelant. but the alvancing merehant fleclines to become a produce beyond the point of orlering sales and closing accounts. If these the actors most nearly comnected with this areatest field prodnet wf the world. Hese each that proprietary interest which 
would make him more than a mere factor w asent, then the State, the Public, We, the People, become the real protucers. Have not we, the people, an interest in the marliet price of at

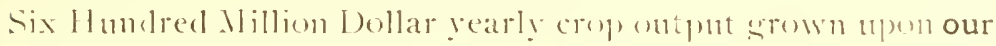
soil, that demands public attention. public promoting and public guarding: Is it uot patent that the sale of this prolued calls Iur a little Harmless State Regulating? Harmless in that it means regulating thromsh elucational work. Slumbl not we, the penple, as a state, save this momer waste by giving to the selling farmer that edecation which womild enalsle him to kmow the sarale of cotton the sells: It is this puint of his inexcusable lack of knowledge which has mate the fiw Hundred and lifty. Million dollar losi possible within the last ten years to the whole people we the cotten section. It is a shame that they remain ismorant of that which may he su easily learned and that they contime to permit themselses to be hoodwinkerd with the story that a knowlerlge nif coltin wrading is an excult science-a emmpoume] enigmatical prol.. lem-that it can be posiesed only by an elect few wh wall. acpuaintance with this special light thomsh a mysterion- cont nection with the gift-sonree of superior embluments.

llhy have on cottom problucers believed this morasmalble

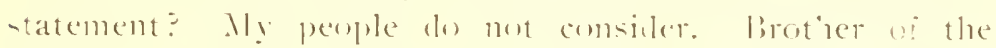

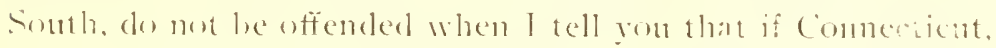
ur any wher of our so-called lankee Stats were a cotum arowine State. within its borders comble not be found a farme' boy fourteen years w age who wombl mot kmow well the srades of the cottom marketed from his father's farm. lint mow is it with us? Wetrust. We helieve, we are leceived. We are mystified, we are innculated, we are saturated, yes, we are literally "strakel," with the false teaching that Cotton Grading is a domble-action, reverserevelving. here it is, there it is.

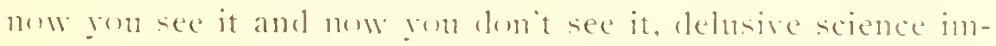
measurably beyomel the seope of a farmers entmprelension. This is mot so. leet m! denial be emplasizerl. 
I will plate one thomsand dollars as a forfeit-a like anmomt


ite fath-that I can instruct a selected boy alose fourteen years of age, resident of the entem States. within a eomrse of thirty dass, so that he will be able to class one hundred bales of eotton ly the sicle of any expert cotton classer. to be known as Classer So . 1, and mot vary from his classing more than atwether expert classer to le kmown as clasiser No. D,

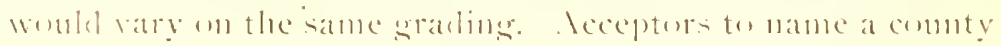
in am one of the cotton states from which I am to select a youth- forfeit to he siven ly rightful custorlian to the chatity w his chossing. The sincerity of this proposition ma! be bent determined by applying the test.

It in this character of commmon schom comble celucation that forms the basis of this appeal. Ne have nur state enm-

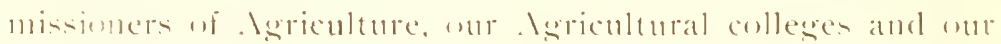
Farm Jommals. It is to be assmened that officials. facultice ande eliters are aceeptably qualified for their respective lines

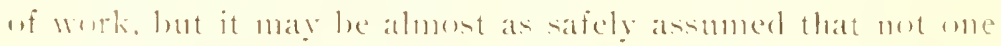

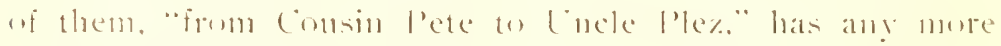
linumbelese of entton watling than if he has been reated in the

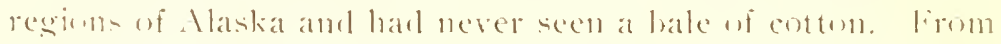
these someces we are to expect but little. if ats! instruction of this character. It Clemsim. \&. ( ., at Ithens. fial. almel at Inlurts, Mla.. small mosements bave leeen male to instruct as state (intton sehouls. This system is helpful. lut it does mot meet repuirements. We the People need that forms of Protection which would he afforeler hy making Cotton Classing ance of the sturlies to be inclurled in the (urriculum af ant

\section{Common Schools.}

Laws shombl be cuacterl in each state repuiring Superin-

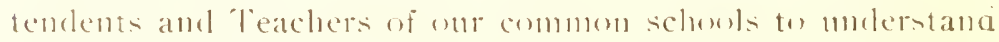
this smbject. Tt shombl be tamght in every school. It wombl cost hut little to put into operation this sytem of instruction. "leachers combl easily qualify and buth they and the pupils 
instructed would find the work pleasingly interesting. And here let it be said that the acyuiring and the imparting of this knowledge is an adlaptability fitly belonging to our Lady Teachers. Innovation as it may be only give them the opportumity, which is easy to do, and good will follow. She whose eye and touch readily finds the quality of a fabric would not be slow in giving the correct grading of any sample of enttom. I set of samples conld be easily obtamed for erery -chool at a cont tow small to be comsidered, and the acompanying Course of lustruetion is a pen picture and explanatory discussion of every grate to be obtained. IV ith such equipunent results would attend bearing the fruit of remuneration-yea, return a humbled fold.

It is not clamed that in a short eourse of sample study anyone may learnall that pertains to cotton and its commercia' travel from the field to the finished porlact. lint it is reasonably clained that the prolucer may easily learn to grade hisuwn cotton and know its market value. This Protects him and it is enough for him to know. This le should know as casily and as well as he knows the grates of his pumpkins, peas, corn and other farm proluce, or as he knows the relative value of any two specimens of live stock on his farm. Let him asquire the simple protective knowledge of Grading and leave all else to the Fxpert who comes out of the supposed di\%y labyrinths uf mysteryland.

\section{Bug Under the Chip.}

If it is suspected that wther than patrintic mutives have inspired the writing of this appeal, in other words :f it is thought there is a bug under the chip. in esspect to the economies do not waste any valuable time looking for him. Though the question "lFor II'hose (iood," should be answred a thousand times, "line the food of All, for the P'ublic fomel," get it is to be mulerstoud, if you so please. t'at tile sale uf 



appeal. I better view for you to take of the matter. luwerer. is to concerle that the origin of Cotton Cors!ing lessins may be traced to a l'ublic Xeed, amb that they combl have been pepared without at thought of personal gase. Cotten (iral-


and smmer or later it will he so tanght. The Cintom Giate -hat stands first in this line of legislation wili have just canse to feel proul of her prosessive stej). Lint if it is thousht by You the People, or by You the Representatives of the People that my bus moler the chij shomkl be killed and kept thea! at an ammal cost to the comtry of Twenty-live Milliom 1)ullars. perhaps the wiser statesmanship will be to sive no enconragement to firating Lessums, and get in line with that sreat financier who spoke so hroally about the condemnation of common folks.

1 direct appeal will be mate tw the sereral lesislatures w the (intem sitates to enatet laws mpon this question. In they ma! respoml, so will the perple be profited. Let every resident

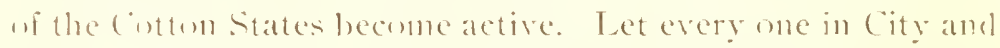
(iomutry ure that the weal of the whole people be suarled that his persomal interests may therelsy be promoted.

ke-pectully stomitted as a fit acompanying chapter t's my reveral works on Cotton Crading.

N. T. McArthur. 


\section{ABOUT PREPARATION FOR STUDY.}

If a full board of simples could be had for use in connection with this lesson, it would be better for the sturlent. If only une sample of each of the seven full grades could be kept in the class room before students, comprehension of the intervening and surrounding half and quarter grades, as describer in "Pen Pictures," womld be much facilitated. A no real exhibit of samples could possibly acompany this work, as a part thereof, an imaginary exhibit has lecen presented. The language and arrangenent of the lessons provide for either a real or a supposed exhibit. In cáse of a supposed exhibit, the lessms become purely theoretical, thomels the theoretical becomes practical as som as real entom is places hefore the student. Lint why, in this land of entton should poverty of supply exist? In any cotton warehouse in a cotton territury a partial. if mot a full set of samples may be easily procured, and if not there. they may be obtained at small cost from other sourees. As they may be had both easily and cheap, a full set of types should be kept before the sturlent as le studies their minute deseription siren herein. Frocure your cottun samples wherever it may be comvendent. of kmown ur unkmown grades. Examine each type carefully and lowk in Pen Pictures for its description. Yon will find it lescribed and its Grade named. These Pictures you can som transler wo your mind, and then wherever you fund eoton and whatever cotton you may find you will kmow its grable. 



\section{LESSONS BEFORE CLASS. CHAPTER I.}

Assuming that you are familiar with the profluet as a field conp, we will discuss the varied comblitions wif cottom in its intermediate position, that is, between the field and the loom or factory. I will take the place of instructor, and you will interrogate. asking such questions as my answers may sussest, or that may wherwise present themselves to gou. Jin ma! proceed now with yomr questionsin.

Q. What is the subject-name of the propmed dincunsion?

Ans. Cotton Cirading or Ciotton Classings.

Q. What is its scope. w what ntility is embraced in this sulbject?

Ans. It sets ont and names the varied conditions just re.ferred to. And entton coming muler the clase ondition of an! particular grade is so named.

Q. Nhy is it se sraded?

Ans. To separate into parts w parcels. according to (o)mdition. for commercial distinction. so that redative valtes may be assigned. ()ur subject. as we will discm- it. embraces in detail these conditions and separations.

Q. Into how many grades has entom inen classed for (u)mercial rating:

Ans. Inte about thirty listinct classificatinss. (1) thesc there are seven full grades, seven half grades, and six quarter grades.

Q. Since these do not malie all of the named numbur. what of her wrates are comprised?

Ans. Other distinct wrade names, a dozen or more in mumber, refor to the color condition of the Full. Half and Onat ar Grades.

Q. What are the names of these grades

Ans. They will be taken up separately and a their charac- 
ter w distinction in considered and defined. to each its name will be assigned. Fisu will later be furmisled a list of the wracle mames as they appear comsecutively.

Q. What is the Thasis of these distinctions?

Ans. It is the length, strength, and corce w eliameter, of the fiber. to which in griven the general name of staple. It this staple or buly, may be goot ot hatl. and as it may be white, ur colored hy shadings. tinges and stains, or as it may be affected by scaling. impurities su it is commercially erracled.

Q. What are the impurities to which !n refer:

Ans. They are trash. sand and motes.

Q. What is trash and its chatacter of impurity?

Ans. Trash is ustally a showing of broken cotton leaves. boll shuckin, grass stems and other dried foliage and vercetable matter that mat hecome mised with the cotton. The cotton leaf is the principal form of trash. and the fince the particles or parts inter which it is cut or broken by the ginning process, the greater the percentage of clamage. I will later show you the relative damaging charater of the forms of leaf trash.

Q. NThat of sand. :mol how as an impurity does it affect cottun:

Ans. Sambl is sometimes lifted into the open bolls hy strong winds. hut the great hulk of the sand foumel in eot tom, is that which adleres to locks of cottom that, after having fallen wn wi the hurr. are picked up from the gromed. Sand adcls to the weight of entton and injures machinery at the mills. Cotton carroing much sand is expected to bear an accompanying tuota of trash and stain.

Q. What are motes?

Ans. Whes or neps are knotty developments of immatme cotton that pass in whole seed form thromgli the win-or they may be seed ends and parts of seed hulls. cut into the mass of lint ly too close. or sharp gimming. The latter kind 
is kmown as shell motes and is usually acommpanied by gin cut w a double cutting of the fiber by the gin. A trace or small showing of metes may be fommd in nearly all grades of enttun. but motes in quantity are highly injurious. They interlock with the gencral mass of fiber and become inseparable.

Q. Vom refer tostain ats a damage, why did you not include it with impurities?

Ans. All forms of damage are to be consiflered impurities. but stains and tinges are color comelitions. The strength of the fiber is usually not affected by the ordinary foliage stain. The pod end or hurr-sink stain has passed the stage of flecompusition. It would clear or shake out in the carding process, but the pod of fibers to which it belonged would be shortened and injured. This character of stain is not fomol in the better grades to any hamulul extent. It is easily recosnized when fomud in the lower grades. ()il stain is the result of crusled seed and is rarely foumd in haled cottent. It is sometimes developed from the fatty ends that pass ont with the simmed cotton. but more frequently it follows the crushing of these seed ends by mill machinery. It is glue-like in its nature and itsurigin, seed motes is eomsielered a damaging impurity. There is another kind of oil stain that follows the heating and sweating of damp eotton in the seed. The exuling oil, instead of making a yellow stain. as with the crusherl sced passes moformly inter the budy of tht fiber. and grives to it a loluish tinge. If this decaying process is arrested in time and the cotton is dried and gimned, a sample will show in most instances. a dead staple of bluish tinge and musty orlor If the strength of the fiber has leen preserved, it may be wrated. but if the fiber shows the effect of rot. it is to be chassed damaced. Frost stain is a cold hlight affecting only late immature cotton. Its presence inclicates a weak staple burly.

Q. Ire the general points of erading embraced in the 


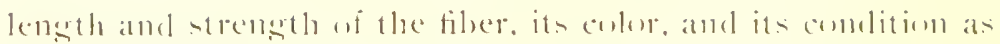
to impurities:

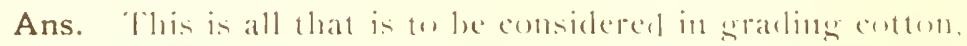
exeept the items of water damatge peparation. amd imequalit! of filerer length.

Q. How does water damage manifent itself?

Ans. Nlater lamage is simply rotten cottom. The wetrims process is the only means of hringing cottom to a comblition of rot-elecas. (intom in labe as in the seed fexplatued) may fecome leated and damased to the exterle of halving its vitality (elasticity) destroged, and yet have a commercial value. The extem of this damage is to be estimated by the claserer.

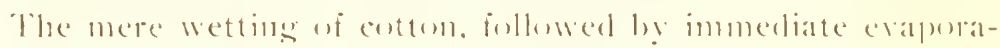
tim, deres mot affect its marliet value.

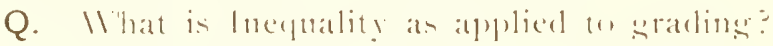

Ans. As the worrd implies. it is a difference in the lenenth of the fibers composing a bulk of eretten. Po the arerase

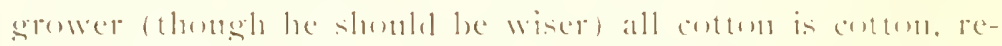
gardless of its eolow or staple. He mixes pickings from his best lamds with the purer quality gathered from thimner suils.

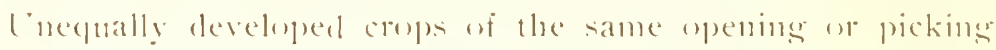



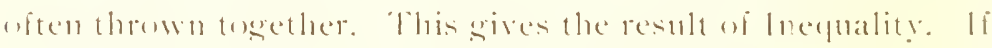

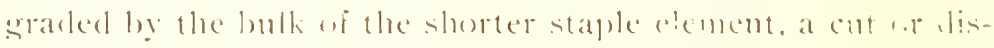
comnt wombl be made in the grate on acemes of this mistme.

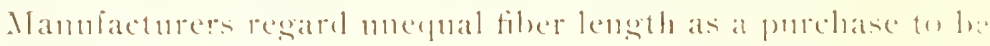
a)imerel.

Q. What is $(1)$ be mulerstond by l'reparation:

Ans. In a general sense it includes the methos sof wathering and subseguent effects from probable exposure. but its

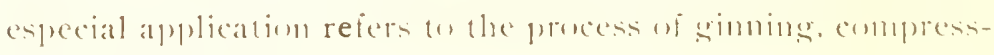
ing and wrappins.

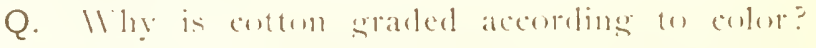

Ans. (intom is appleciated by mambacturers for its charater, as it may give at least enst thromgh processes of 
mannfature, the hishest grate of finished probluct. The whit

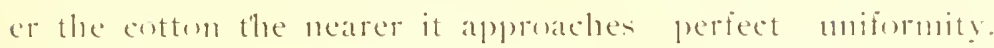
This muformity is maintaned in the process of bleaching. and notwithstanding the claim that some of the tinges and stains are easily eliminated. extra expense is imoleded, and the ahsence of moformity is feared.

Q. Does this lack of moformit! alpleat followitns the dreing procenters?

Ans. That it deres mot ar maly mot is lue te treatment involving extra expense and to a thorough mixing of the fiber before mamufacture.

Q. Lefore proceceling inther will you again explanin fully the cencral entitions named affecting the chanatede of enttom ats they may be applied in arading?

Ans. Yen: but l will de this in a separate lessurn. I wil!


previonsly presented and log this repetition prepare you better to emmprehemel the imaginary sample exhibit, type by ty. as they are unfolderl to your inagination. 


\section{CHAPTER 11.}

\section{A Discussion of Impurities, Stains, Trash and Other Demer- its.}

In entering num this separate discussion of lumpurities, I will first comsider Stains, showing eateh an it appeats ats a lamarringe anent, and explain its origin, at well as its effect. I will first present

\section{Boll Stain and Burr-Sink.}


calsed by rain falling upen and entering inte the upen pod of entem. The coloring matter of the immer hurr is absorbed hy the onter presented arface of the enclosed cottom, and this stain is the result. In minimum quantitien it mat lee

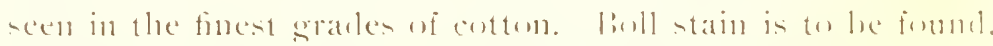
therefore more ar less in the whole descent of errates. 'This -tain is nut to be confounderl with the liurr-sinls stain. though both result from smilar catues. The Burr-sink stain is the decpl-seated lecayed end of a lock on section of the boli

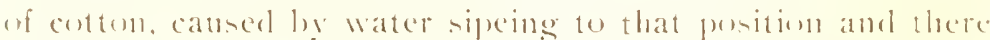
remaining till a sticky cementing form of decomposition is bronglet into action. The liurr-sink stan. where it appeats in at sample exhibit, indicates that une of the sereral locks of cottom in its producing boll has been shortenet. This shortening hat for its effect. Inequality of filer length, and though the feathcry-like stain is easily leaten ont of the exencral mas. and is therefore comparatively harmless as a stain. where it is seen in guantity. the element of Inequality is to be sulstituted as a srade reducing factur.

\section{Foliage Stain.}

Foliage stam, next to he described, in its milder forme. 
bas been included with lioll Sitain. but there is a market distinction in their effect respectively, as the degree of wrat magnitude is approached by each. Exasererated linll Statiu or its continums formation would probluce burr ret, and a conseguent damage to the enclused bull. As Foliage Stain is only the colored washings from the cottum leaf. thence drip)pings upon the open boll dry away and leave at stan which has not affected the length or stremeth wi the fiber. The entoring matter is originated log a puncture of the cottom leat. coming foum the feeding muths wi insects, nearly ins isible in form, that may be fomml feasting therem These cut intu the tissue of the leaf and, as stated, rain washings are colned, giving the result of Foliage stain. Wlibe entomologists and botanists are left to harmonize their varying opinions as tor. whether Cotton Rust is a constitutional tromble coming from a diseased stalk buly or whether is is cansed by multiplicel millioms of foliage feerling fungi. we will pass on to results in the form of stain and in imagination view sreat fiekls nf upening cotton that have been werspread ly this blight. Is the Rust works its devitalizing force, gentle rams ma! probluce the above described effects till almost every fiber of leveluper cottom in those fickls will hear the markis of Foliage Stain. The staple bol! womld remain maffected hy this areat fyeing of stain. and if cotton of this kind shomlel -how freedom from


fication.

\section{Oil Stain.}

Oil Stain proper. is the stain caused hy erushed seed in the lint before ginning. It is of a greenisly rellow cast and is casily distinguished from other stains. The circumstance- would be indeed peculiar that would furnish a luale of cotton affectert thronghout by crusher seed Oil Stain. As a damaging impurity its appearance in cotton at the factury in regarlecl a- beins 


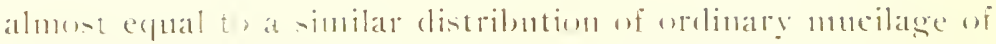
a like quantity. It alues the fibers together in such manner that they are wot easily separated. This stain is rarely fommd in a cotton exhibit. lint a nice stanless exhibit may caryy concealed, in the form of fatty seed ends or whole secols, the ()il Stain so much to be dreated. As these pass through the mill machinery they are ermsherl and the exuding oil becomes absorled be the surrounding fibers. Oil Stain, therefore, is

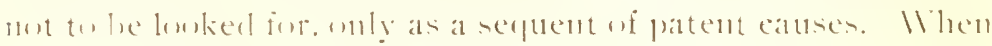
thene described catuses are follul in atl exhibit, they are to be raterl an Oil Stain. Seed Oil Stain is the effect of damplesis causing its lecal: The proess of decomposition of the enmpact mass uf stored dampeotum hegins with the seed and the first step of dissulution is a parting with the sil they comtain. This oil, as if cosnizant of the fact that a new home most le foumd in place of the decaying shell it has orempied.

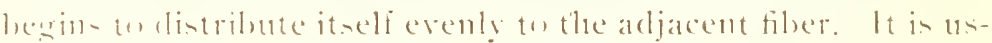
nally during this process of distribution that the entum in

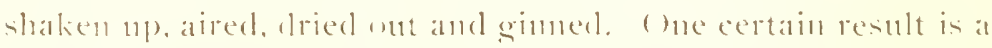
yenteral seed-sweat enloring of a eombined yellow and blusis tint. I secombl restet is that the fiber. though chatresed with wil sems a levitalized. and it is this principle uf alsent vitality. as it is more or less to be moted. that determines how much

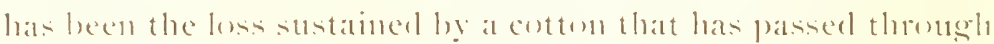
this process. The stages range from a slightly coloned. lishtly affecterl fiber, wh the nposeite extreme of deep tinge and must! nlecay. Discoloration is the most frequent appearing damase.

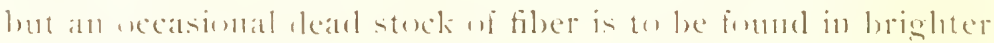
exhibits. Is leng as the lueking or intertwining twirl remains the fiber is emol, when this quality of life is alsent, the fiber is tole condemmed. I mere movice enold determine the difference letween live and lead onton, that is, kmow mpun examimation whether the sample exhibit was live and shomer the -joral twirl, or was deroid of this principle. 


\section{Frost Stain.}

All bolls of any late crop that are nipperl by frost before maturity or before opening, show its blighting effect. If the frost is severe it reduces some of these younger bolls to a watery pulp. ()thers a little oleler escape this extreme, but "pen only in the form of hardened enclosed pods. () thers still, which are nearer mature, react from the chill and open under effect of a warming smohine. It is this process of reaction that causes the inner parts of the burr to dye or stain the pod of fiber This character of stain is easily distinguished and indicates not only a short and immature fiber, but a weak staple. If such late pickings should be mixed in any appreciable propurtion with better cotton the whole is reduced in wrade therebs. If a part of the middling crop shomld be gathered with this Frost Crop, it would fall below the classification of Low Middling. Following this fact, the half grade, Strict Good Ordinary, is only a lower Low Middling, the body "If which is supposed to have a higl character of strength. therefore, if any weakness of staple should show as a result of the mixture. Good Ordinary would be its highest gracle mark. This. however, does not point the limit uf descent. as a predominating proportion of Frost Stained cotton in a mixture that also carries other damaging demerits misht be borne down thereloy below the sonje of commereial estimate.

\section{Mildew.}

This form of refect is patent to any observer wherever it appears. It needs no particular deseription. I bale of cotton may become rotten on a part of its surface, and still have its interior sound. To separate these properly repuires only the discriminating julgment of any careful examiner. This stain has also been called Fungoid, so named from the scientific causes attributable to vegetable decay. 


\section{Hoop Stain.}

Hoop Stain is the result of damaging exposite to water. either from rains or from contact with the carth. Whether from mist. spray or rain, it is easy to julge how much ottom of a bale may be on damaged. If the jacket or ener shomlel show signs of rot. a critical examination of the hale shomlel be made, as an interior clamage might possibly be traced from these inlications. I chely compressed waterpated bale of cotton kept in a damp place would show Hoop Stain, as it might alos slum a hadly damaged interior.

\section{Soil Stain.}

Soil Stain is a coluring or shading inparted to cotton by loarlings of dist gently deposited from the surromoling atmosphere, or more violently lifted and carried into the pes from adjacent soils and territury by stirring winds. The dust and wril bearing sand thus deposited permeate the open boll, and distribute an eren shate of dust-color to all parts uf the receivinge porl. So insinuative is this form of light dost that it seems to buse its character as dost and wo become part and pareel of the fiber where it is deposited. If the dust has been dark a corresponding shate of "off color" will show in the cotton affected. It is this shadling from dark dust that gives to the White Grades of cottom, from Good Middling to Low Middling, as it may be but slight or of deep cast, their distinctive features or complexiom. If a deeper shatle than the face of Low Middling shomld show on a fairly clean standarel staple the color would be placed in the category of Tinges. All red dust affecting conten in the way I have just cleseribed, inparts a redelish color, and all grades so affected are denominatcd Tinges. Soil Stain as a result of storm w wind beaten cotton conning in contact with the soil direct is colored according as the soit may be colored. This field stain does not 
affect the cotton only at and near the points of contact. In consequence the stains are nut general. but appear in sputs and "splotehes." and wive as an wutput the varjous wrading foum the highest Stain to the lowest mark of Stains and Tinges, according as the staple body may be otherwise varyngly affected. Formerly a large percentage of the arlhering sand went with the mass of cotton thromsh the gin and inte the bale, bnt modern improved methods of clearing from sand at the gin lave in a wreat measure climinated sand at an impurity to be fonmel in srading: yet it must be lowked for. and if by exception to the rule it shombl appear. it must be measured first as to its estimated weight and secombly as to its injury to machinery at the mills. In every quade of eotton, from the highest to the lowest, small particles of grit or samd are to be found. hewever. it is only where sand is fommd in larger fuantity that it is to be consielered an impurity.

\section{Tinges.}

Natural tinges are little to be comsiclered by the clasisere. Variety, soil. smoline and atmosphere are agents prolucins many different natural tinges. The Brown Egyptian, the Red Peruvian, the Yellow Sea Island and our own slightly reddish Tinge found w the reel fields of the Uplands cotton belt conld nome of them he probluced except in their present buown indigenons solis and atmospheres. (1) these it is anly necessary to speak of :

\section{Uplands Natural Red Tinge}

This Tinge is with difficulty distinguished funm the Red Tinges produced by dust discoloration. Its color is of a clear, pinkish red and is only yeleled in the higher grades. Freakish as it may appear. the same stalks that qielsl a Good Middling arate of Natural Red Tinge, would produce a later (mop) of White Middling. In grating we can only apply the law 
worerning as to tinges, griving to it the benetit of all woubtful prints of arate merit. The cream colosed cottom of the high stalle is alsor a Natural Tinge, lut it is graterl as a White prouluct.

\section{Red Tinge.}

111 Soil Stain, having red flust ats a prolucing caluse, is ararled as a Red Tinge. It corers the entire list of commercial saldes. In leterminimg any grate the same law that gov-


ever. that a tinged araling will cary a slight athlition of impuritice abuse that male for a enersponding White cotton. Pon sureat a difference in assigned value is supposed to be the hasic reason for this allowance.

\section{Dark Tinge,}

Inain I will refer you to my remarlis concerning Soil Stain. Therein I told you that it was this sharling of I atre Tinge that in part, wate (omplexim th the Grade Face wf all the Gradings, from Good Middling to Low Middling. I lirl nut incluck the narlen w Good Ordinary and Strict Good Ordinary fur the reatsom that. lhumble it might in certain inslances be aptly applied. wher stans and tinges are mone frequently fomel. Ifter dealing with these colorings in that way we may take all soilstains abure that uf a Low Middling in shate aml talss them at Dark Tinges. I pumbur prejulice astuist this "Off Color" keeple it in the luser srates of Tinges, Middling Tinged he ing abent the highest limit allowed. I mully appearing exhibit uf utberwise woud enttom has heen classed locally. in

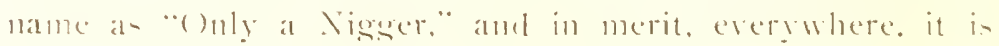

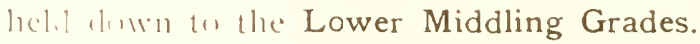

\section{Smoke Tinge}

It in mot imposible for the particles of endoring matter in 
smoke to be wafted at listance ats weat as that form l'ittoburgh in Pennsylvania to the cotom fieldo of Mestern Tixas and Oklahoma Midlocean is said to have its smok! days. These particles of coal smoke from different prints we wen unite. and form sereat blanket-like clouds and in settling form a dark leposit on all material at the point of descent. For whole seasoms. clombs such as these follow in successiom and resulated by some muexplained law, settle in the same territory. More, the aremes of transit secm so routed that annual ristations of this kind suceed their preceding leat motil we have a fixed territory from which we may expect to receive cotton to be sraded as a Smoke Tinge. This territory includes a broken or irresular section, traversing the entire cotton belt, and included between the hill breaks abme to points within fifty ur sixty miles of the sea-cost. There may be long waps in the line of its appearance, but wherever fonnd it is the same, and traceable to the same character of cause.

Smoke Tinge is sraded just the same as Dark Tinge. Growers have attributed this Tinge to local causes, such as having fields approximate to smoking furnaces, and near where many locomotives pass. It is possible thus to discolor a field of cotton withent conflict with the eneneral aecepted law. which I have just act out.

\section{Blue Puff.}

- Blue Puff or Smutty Puff as it is smmetimes termet, in eatsed by gathering the whole porl towether wherein there is or may be a perished and elecayed lock nf entton. lisight of this kind is often formel in a field and wne bull thus atfected to each fifty taken is sufficient to blacken the whole combinat tion. This tinge or stain sometimes shows in limited quantities and is then to be estimated as a stain affecting the general Sample Exhibit. But if the tinge shows to be general, coloring the whole borly of cotton presented, the cotton must be placed on a low grading, as low at best, as Low Middling Tinged. 


\section{Trash.}

II 110, (ande to comsider Trash in its place as an Impurity. folliage trash. that is. leat and bols shuck crumblinss. comprise the principal forms of trash fomed in cotton. Dry weeds and grasses maty he in cottom where such trash is permitterl to sum to maturity in the fields from which it las been taken. Foliage trash. (inclueling the bull shuck) is mute damanging in its broken parts. as it is crusheel inte small or finc pieces. The fince larts are kmown as Pepper Trash.

lepper 'lrash has usually a dimension expal to from wne thirty-second to one-sixterentle of an inch dianeter. The smaller lust-like particles that sumetimes mat the face of an exhibit, are simple forms of dust that may be shatien wut casity in the processes of cleanme. I mere casmal examination will show a distinctive difference in these for:us of inmertities. With the regular foliage Pepper Trash the fiber enthraces these small parts in it menh like holde and it is next to impussible to elfeet their release. Larger bolies ne leaf


to remone. The locking filere cammentasp them in their entirety as in the case with the intermediate forms ame the still sllaller pelper trasto. () f course the quantity of this trash as well as its quality is to be ensidered in grading.

cotton enets its loaling of trash frepuently thromgh carelessness of the gatherer. hut often pondential canses rembler such badlings manoblable. I field of upen cotten may be werrum hy fecling wormes The result is the worst forms of litter and tras are colt intu the (1)

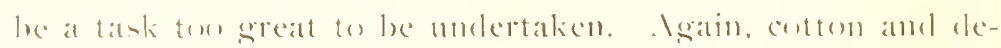
cater foldage from the stalk. and all other dried regetation might be driven by winds and stome intw an ineongruons mixfure bi enttum and trash. The eottom must he saved and not musually after being cleaned as carefully as possible it shows

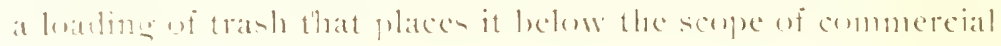


wraling. Is to the amomnt of trash allowable in different grades. I will take the suljeet up in this phase, in a separate ennsideration of the list of grades to be exhibited.

\section{Motes or Neps.}

Cuder the name of Motes, nearly all wi the impurities following upon bad gimning hase been gromped. Whole seeds. broken parts of seeds. seed ends and the fibers that become separated from the general mass to wiml themselves about the heavier forms of trash, in fact all fibered massen detached from the smouther layer of the main body are to be designated Motes. These fibered masses may be cleared by the cleaning processes at the mills, but such separation inmlves the probable loss of other fibers or parts of fibers to be caught up in the severance. This latter probability leats us to presuppose the introduction of broken and shortened fibers into the cleared mass, by which it would be to snme extent reduced in value. Is to whole seeds and fatty seed ends I have just pre-ented this plase of Motes in nul discussion of Oil Stain. Motes are comsibered heary impuritics and because of their tenacity to the budy of fibers abunt them, they have heen classed to that extent. Inseparable. Ismall trace of Mhotes. an recasional immature seed, and the shell w split hull also, at incidentals, may be found in the higher wades. lint Motes indicate bad simning and when fomnd in fuantity are usually accompanied by suin cut. Therefore where Motes are found as a prominent impurity cotton is to be placed in the lower markes.

\section{Sleek Heads.}

Unripe and Dead fibers are to be found in all grates of contton. If omly a trace or small showing is presented. they are (1) be regarded harmless, but as their nmmber or quantity increases. they begin to call for recognition as a damasing foa- 
ture. Sny catuse that would hinder the derelopment of at boll uf entrom, or even one luck as a part wi a bull. would grive the result of half ripe. or as it might be dearl fiber. lilight. such as rust ur black root produces, might fall upoul a field, carrying with its larewer part of fully mattred bolls a fair percentage of half-ripe as well as less developed bulls. the greater number uf which would wpen, cither wholly, w partially, hut sufficiently to be sathered and mixed with the mass of full ripened fiber. lu such a mixtme we shomlel see mumbers of little threatlike fibers which had not Heceed out as they left the gin and which would now curl wp intr something like the form of an interrogation point, as they womld present themselves in the general bocly of the fiber for observation. Igain might be secen numbers of small fattened sulstances encased in the sleck folding of the immature part of the producing burr. for this is cotten to which has allered the original pulpy part of the bror, that had fallen far short of maturity. These showings monld hose in measure of both length and strength as compared with the seneral mass of the holy hearing them. Is a result the feature of lnequality is presented to be estimated in srading. according to the quantity exhibited

\section{Gin Cut.}

This feature of elemerit has becen referred to in so mans instances that it must he alrealy well molerstoud. It is the severed parts of fiber divided into two or more lengthe he the gin at it may be tow shap or griven tw high a rate of speed. By the present mode of (listributing the enttom of a single bale to a system of a half droen or more wins, all moving at the same rate of speed. but no twr, perlaps. regulated alike as to cutting capacity, it is remarkable that win cut is not more generally encomutered. It is mufortmate that the innerestapled cotton suffers most from this double cutting. It is relicring. however. to know that where only a few saws of une of a Jarge system of sins may probably be loing this disastrous 
work, the proportional part of Gin Cut falls to a consequent lower percentage of the whole. Gin Cut is a bad form of Inequality. It shows in a Sample Exhibit with the cut parts lying across the even general layer or stancling out like the bristles of an angered animal. As lefore stated, in a snall way, it appears in all saw-ginned cottons, hut where it is frund in marked quantity the yrading descencls acenrdingly:

\section{Gin Roll.}

Gin Roll is the rope like mass of wet cotton which does not leave the gin freely and is twirled into this form by the process of clearing the saws. It does not affect the value of the fiber but its presence usually points to Gin Cut.

\section{Water Pack.}

Cotton that has been ginned and compresied in an extremely wet (or steamed) condition is classed Water Packed. If ty any means the avenues of evaporation should beconte closed and the included compressed air should find no means of escape, fermentation would follow and rot would be the result If the Cotton las been "wet down" between the gin and the press, with the view of increasing weight, the dampness would be less generally distributed and, as a sequence of concentrated puddling. decay would he more probable. Much depends upon the age of the bale or the length of time intervening between the date of packing and that of its examination by a classer. If the bale is presented fresh from the press, he should wrade with full allowance for the extreme conditions I have mentioned. But if the bale had that age which would allow it to present a dry surface, examination by deep boring or cutting would determine its state as to soundness. If no signs of water damage shoull appear, the cotton would show only a slight discount of grade on account of having been Water Packed. Otherwisc such tlamage as 
might appear would be estimated by its extent. Water Pack is evidenced by the way rolls or ropings on the sides of the compressed bale and by slightly colured lines between the edges of the layers, produced by the emission of water at these points. A sample exhibit from a restored baic of Water Packed cotton has the wrinkled appearance usually to be seen in a fabric that has been washed and left unironed. Water Pack is so rarely found under the present system of preparation, that I will leave the given description as sufficient.

\section{Flexibility.}

Flexibilty is the elastic principle of cotton that enables the classer to recognize by clasping in the hand the fine or coarse quality of a specimen exhibit. The response to his touch or clasp informs him quickly as to whether the exhibit is a live. responsive specimen of the higher grades or whether from brittleness, roughness and a sleepy or slow form of stasticity it is to be placed in the intermediate or lower grades The extreme contrasts of the features of flexibility may be likened to the difference you would observe in the respective hand clasps of a fresh handed school boy or girl and that of the hard handed daily laborer. The vital principles of an exhibit are to be measured mainly by its flexibility, though loadings of trash and other affecting causes serve to reduce this quality.

\section{Inequality.}

If you have followed me closely in this discussion, you have heard frequent allusion to the character of Inequality. You doubtless know that it means unequal length or strength of fiber In each reference I have made to this condition, I have mentioned the cause producing it. Mixed products from the fields, immature fiber, gin cut and other causes have been discussed, and your acquaintance with the subject should consequently be well established. Spinners desire fiber of nearly 
uniform length. It is known that fibers of distorted length will not run or work out together, and that the cost and annoyance attending their separation at the mills is reckoned fully equal to the value of the shorter parts extracted. Therefore in an estimate of an exhibit carrying an objectionable quantity of short fiber, its comparative weight with that of the affected body would be considered a fair amount of loss to be estimated in depreciating its grade. In my published work on Grading, a copy of which you have before you, the full text of this discourse is treated. Read it carefully and you will find therein the full essence of the subject as I have here treated it orally.

\section{Note.}

The Author was recently called by its college board to give a short course of Grading Lessons to the graduating class of the Textile Department in one of our Southern Industrial Institutions. The foregoing with only a few changes is an exact reproduction of a preparatory address made before that class, in advance of a practical study of the subject to be made by examining and classifying a large array of samples, embracing many times over the full variety of grades. He has deemed it fitly appropriate to make it a part of this publication, considering that if it were an exact rehearsal of the matter to be found in The Cotton Grader and Grade Notes, it would be good just at this point in these lessons to emplasize all that is to be found therein. It is published as a part of these lessons and is given the exact position in point of presentation that it had in giving to actual students practical training in a course of cotton grading. 


\section{CHAPTER III.}

\section{Continuation of Grading Lessons}

Q. We have lintened attentively to mon discourse on cotton and the varune conditions affecting it, and now will you show us in a practical way the application wf your lecture to the science of cotton classifying?

Ans. Yes, and $w$, lo this I place befure you a pivotal or centrally characterintic type of each of the Eighteen Current Commercial Grades. (See Plates.)

Q. What are the mames of these grarles?

Ans. Taten in their descending scale from the highest to the lowest they are named Fair, Strict Middling Fair, Middling laar, Strict timnl Middling, Cood Middling. Strict Middling. Middling. Strict l ow Midelling. Low Middling. Strict Coud (Ordinary and liood ()rdinary. These are known as the White Grades. Then we have Strict Good Millling Tinged, Good Middling Tingere, Strict Middling Tingerl, Middling Tinged, Strict L_nw Midlling Tinged, Low Middling Tinged, and Middling staned, all conprising the eighteen Grades mentioned.

Q. Will Inu explain the terms "pivotal" and "centrally characteristic," as you have used them in referring to the types before 11 :

Ans. These terma refer to the complexion or face color of the types and to the falces themselves as each may be affected by a dissimilar showins of impurities or by other peculiar lines of lifference. They show one opening or face of the sample exhilit only, and irmm this face, as presented to our view, we are to conclude onther openings and faces to be the same. That is, we are to determine the character of the grade upon vision, or "How it lowks." 
Q. Is vision alone sufficient? Is appearance an infallible guide to a definite placing of grades?

Ans. While in the main, any type or grade of cotton may be recognized by its face, verification of a decision so made is established through the sense of Touch. What is known as "body" or staple character, the length and strength of the fiber must be determined by feeling. It is very rare, however, that "hand examination" fails to coincide with indications presented on the face of a sample exhibit.

Q. Shall we not be permitted to handle the sample exhibit before us?

Ans. Continuous handling woukl so wear the face of a sample that its characteristic features would be changed. It is better, therefore, that we use these only as guide types, preserving their faces intact for study and comparison.

Q. Are the several color casts or gracle complexions, and the showing of Impurities as they appear in these types to be accepted as the exact allowance for each of these grades?

Ans. No; there may be slight variations of both Color and showing of Impurities. A little more or a little less of one or both might appear and still fall short of a quarter grade, above or below. This is a law of variance applied in grading, but it is usually found that the variations of Color and Impurities offset each other, an increase of shade being met by a compensating decrease of Impurities. As I have stated, however, these types are centrally characteristic, ir pivotal, and no graded samples of cotton compared with them will be found to vary in any significant degree from the faces here displayed.

\section{Fair.}

Q. What is the first type in the line before us?

Ans. It is the highest grade of Uplands cotton and is designated Fair. You will see that it is almost purely white and that it is free from all the blemishes I have described as Im- 
purities. At the foot of the type I have combed out a mass of fiber which shows a uniform measurement of one and oneeighth inches. It is not excessively long and fine, neither is it coarse and brittle. It is a good specimen of Fair Cotton.

\section{Strict Middling Fair.}

Q. What is the next type which seems to have exactly the face of the first?

Ans. It is to be graled Strict Middling Fair. The color and the staple are the same as for Fair, but you have overlooked the particles of trash that show upon cluse inspection. These reduce it in value to the descending half grade.

\section{Middling Fair.}

Q. And what is the next of these white types classed?

Ans. It is typed Middling Fair. You will observe that it is as bright in color as the first grades, although a faint shate of difference would le allowable. The fiber also shows a gool character of staple. but an increased showing of trasth and tracings of stain gives it the lower wrading as typed.

Q. Do these three types constitute the entire grouping of the Fair Grades?

Ans. No: the complete group includes three Quarter Grades; viz.. (1) Bareiy Fair, which is a close yrading between Fair and Strict Middling Fair; (2) Fully Middling Fair, an intermediate hewen Middling Fair and Strict Middling Fair, and (3) Barely Middling Fair, a Quarter Grade below Middling Fair. The (buater Grades are not at present used in classifying (sece late of issue) but a return to this minuter classing may be cxpected at any time, according to the whims or purposes of the American Cotton Exchanges. In this connection it is proper here to state that the grade of Middling Fair is the highest grade now quoted in our domestic market. 


\section{SECOND GROUPING-MIDDLING GRADES.}

\section{Strict Good Middling.}

Q. We observe a change of color in the next sample exhibit. Where is it to be placed in the list of Grades?

Ans. We are next to consider the Grouping of Middling Grades. The type before us is Strict Good Middling. As a grade. generally, it is one of the strongest types of cotton both as to natural condition and cleanliness. It shows often a better body than the higher classed Fair grades, but on account of shade or color it is placed lower in classing. The type under consideration, as you see, is of a rich, whitish cream color: showing too little of the cream cast to be put into the list of tinges, and yet too deep a shade to arlmit of Fair classification. It is comparatively as clean as the higher grade of Middling Fair, and its combed fiber shows a strong staple, at least nine-eighths of an inch in length. This type embraces all gradings of this grouping above Fully Good Middling, and as a consequence. classifications of this title citen show marked legrees of variation. This is explained by the statement that a cotton which might be classed higher than Fully Good Middling (a quarter grade) would be placed in this classing, while, with color debarring, the highest merit could not raise it above the grade of Strict Good Middling. The name Strict Good Middling implies a higher superior grading of Good Middling. Color is not an arbitrary or ruling characteristic of this Grade. The brightest and best boclied types of Fair cotton, if too badly "loaded" with trash, or if they should present other indications of demerit, would be classed down to this Grade. (Note previous remark on this subject.)

\section{Good Middling.}

Q. We see a very close resemblance of face in the next 
type to the one we have just discussed. What is its classification?

Ans. It is to be classed Good Middling. The likeness you have observed could be appropriately termed parental, as this is the basic grade of the type we have just passed, and which on acconnt of its better features as to impurities, we classed as a Strict Good Middling, thus placing it a half grade higher than the basic sracle of Good Middling. If not already so unlerstood, I will explain that the term "Strict," when used before any grade name defines that gracle as being ratised to the middle or highest point in ascent towards the Full Girade above. It is the term used to signify all half grades. Apropos to this explanation 1 will say that any commorcial name given to a grading of cotton, though it should be designated whole. half ur quarter, stamps the same as a full type of grading. and it is, therefore, to be estimated as a distinct grade regardless of the distance above or below a basic whole grade. In this typing of Good Middling you observe the same color and fiber length exhibited in the preceding type. It is a basic granle and you shonld give close attention to the face it presents. fou observe two pieces of large or fleak trash fone smaller or intermediate in size, and only a few dottings of the finer parts uf "pepper trash." There are two very smal! specks of folliage stain to be seen and we may also see indications of immature fiber. These impurities are allowable and the type is to be accepterl as a standard Good Middling. I have elsewhere stated that the cream cast of color frequently found in the Good Middling types is a change or departure in color from the pure white of the first general opening, as it is also different from the paler white of succeeding upenings. This does not apply as a miversal rule. In many instances thes creamy tinge does not appear. Therefore a shade of white falling below Fair may be taken also as the type-color of these srades. 


\section{Strict Middling.}

Q. Now we come to a noticeable change of exhibit. By what name is it to be known?

Ans. It is a specimen type of Strict Middling. In its color you see a free white only slightly shaded by dust and stains. Lnprotected by the greener and consequently denser foliage which shielded the higher grade openings it shows a slightly lower degree of complexion. Next we notice on its face increased showings of both trash and weather stain. This is due to dryer foliage and exposure to rain. We see, also, curling fibers or sleek-heads denoting a small falling off in uniformity of fiber length. This, however, does not show to a harmful degree in the combed fiber, which measures above an inch, and appears to be of fairly even length. It can be accepted as a full rounded type of Strict Middling. I will refer you to a characteristic description of this grade to be found in "The Cotton Grader."

\section{Middling.}

Q. What is the type we are next to consider?

Ans. It is the Grade of Middling. This is the basic or central grade with which all other gradings higher or lower are to be compared for assignment of degrees of variation, better or worse, that a consequent placing of name and value may be determined. It is a knowledge of the character of this grade and an acquaintance with the degrees of departure therefrom that enables the classer to name properly, or approximately near, the entire line of varyings comprising the system of cotton classing. Only know Middling and the scheme of grading may be easily comprehended. In this type you see a shading of the complexion which may be lescribed as a "step down" from the type of strict middling. We observe on its face four of the intermediate breakings of fleak trash, besides numerous dottings of smalnor breakings. There 
is also a sprinkling of pepper trash which, if we are to be pr: cise in our estimate, I should say, if generally distributed, would average about four forms to the square inch. There is a single small blur of stain to be seen. Next we see the indications of unripe fiber but not in sufficient quantity to establish a marked degree of inequality. Finally as we inspect we note that the combed fiber is a full inch in length. fairly

suniform and of apparent perfect soundness. By comparing with the higher grade of strict good middling it is easy to see that its fiber layers are not so evenly presented, and that other graceful features of that type are not fully observable. It is. however, a substantial representation of the great mildle bulk of the American mplands cotton crops as they are now sathered and prepared for market.

Taking this bulk of output for the last quarter of a centur: and we would see that there has been but little change in the appearance of its face as it reached the factory. Hence the original type of middling has remained unchanged, and it is patently plain that it must so remain-Exchange ruling and Government Standardization to the contrary, motwithstanding, until there is a change in the methods of producing. gathering, ginning and preserving the great central bulk known as Middling. An improved output would give us an improved Middling. Lntil such time and event middling will be Middling. It is not at all improbable that some system of wathering by machinery may bedrught into vouge. In such case a lower type of bulk or midaling ewe night be presented. You are to remember that this type is given as a central or pivotal sample exhibit of michlling. Lariations allonvable in both color and impurities will be discussed in a future refer. ence to this Basic Grade.

\section{Strict Low Middling.}

Q. What is the type next in line? 
Ans. It is Strict Low Middling. Its complexion is a degree lower than that of Middling. We see also heavier loadings of trash as well as increased showings of stains. This is a later picking of the Middling crop which has been darkened by a dust deposit to a shade, placing it below the limit allowable to a Middling Variant. It is also proscribed such entry by its increased quota of Impurities. Observe that the quantity is about double that shown on the face of Middling. let its combed fiber shows to be as long and nearly as uniform as that of the higher grade. The lower shading and increased loadings and staius are the natural results of delayed gatherings.

\section{Low Middling.}

Q. We see that you present one other type of this group, what is this grade?

Ans. It is Low Middling. As its name implies it is another type of Middling Cotton reduced in grade. Observe that its color shows the regular and continuous "step down" in complexion. The increased measure of trash and stains are plainly visible and yet it, too, combs out a fiber only slightly below that of middling, in length and uniformity. I will call your attention especially to the facts that a cotton of this color could not be graded above Low Middling though comparatively clean; and that a cotton of any brighter color with loadings of the type before us could not be placed above that grade. Yet we find a pivotal type of Low Middling bearing the demerits of both dark color and impurities. This rule will apply to all central or pivotal grades, but we are not to understand that in the less pronounced types, offsets of color and impurities the one against the other are not to be reckoned. This concludes the line of Middling types and now we will consider others. 


\section{GROUP OF ORDINARY TYPES.}

\section{Strict Good Ordinary.}

Q. What is the next gromp; and what is the type we have first to consicler?

Ans. The types before us are a part of the Ordinary group. There are only two taken and they mark the limit of descent in commercial grading and rating. The first is a type of Strict Good Ordinary. Yon will observe that it is a shade darker than the types of Low Middling, that it carries a slightly increased degree of impurity more than shows in that type and that its face is marred and blurred by knotty looking bulks of fiber. Its combed out fiber shows greater irregularity of length, ranging from seven-eighths to an inch in measure. This is due to a mixed gathering of the Middling erop with the shorter stapled later secomel or top crop. The Middling staple shows weather stains, and trash that has been unavoidably taken in the hand grasp of the picker, either from the ground or from dried plant foliage about the burr. The later opening of top or second crop cotton if separated would show a clean white exhibit. But the mixture before us shows a dark faced unclean type of cotton, the irregular fiber length of which gives it a small discount in value, but having a sound body of good "breaking strength," it is accepted on the market as a spinable cotton, lowered in worth by inequality, color and impurities.

\section{Good Ordinary.}

Q. What is the other type of this group?

Ans. It is classed Good Ordinary. With only a slight increase of shade there is a bolder showing of stain to distinguish this face from that of the preceding type. The material points of difference are the ineouality of fiber length and falling off in fiber strength. This type is the output of gathering 
that includes delayed and weather worn middling with all that follows in the form of late picking. A sufficient percentage of Frost Stain is presented to warrant a cut in grade and vilue on account of reduced fiber strength. A small introduction of Frost Stain is admissable in this grade, but where it predominates as an ingredient or even shows in excessive deuree the cotton bearing it is reluced below a commercial white grading. This concludes the full classing of commercial white types and we will next consider the colored cottons.

\section{Tinges.}

Q. What is the array of types you have arranged for our inspection?

Ans. They are tinged type equivalents of the White Grades we have just inspected. Beginning with the highest type, which is Strict Good Middling, I have placed each opposite its equivalent in the line of white grades down to and including the grade of Low Middling. You will observe that the Tinge is the only characteristic point of difference in these gradings, as each of the named types corresponds in class. In this array the Red Tinge only is presented. I will quote from my opening lecture by remarking that the dirk tinges are assigned to the grade of Middling, Strict Low Middling and Low Middling. The dark tinges of higher types than Middling are usually classed Low Middling White.

\section{Middling Stained.}

Q. What is the lone type yet remaining to be wrated?

Ans. It is Middling Stained. It has an apparent cleaner face than its White equivalent. However, on account of its pronounced imprintings of Foliage or light Boll stains it is so classed. This closes our study, for the present, of these types. I will say to you that a familiar acquaintance with these exhibited types and a memory of my explanation as it has been 
given relating to each separately will give to you, the student examiner, an open way to the field of cotton grading. A knowledge thus gained is like a light thrown over the whole field to be explored, as it may also be compared to a pool where the young swimmer has acquired such capability in the art of swimming that he may venture with confidence and safety into any nearby nnexplored waters.

\section{Rating and Classing.}

Before parting with you at this time I will refer to the confusion of gradings so puzzling to the inexperienced classer. arising from the placing of entirely different cottons in the same grade. In such instances as where two different cottons have been assigned to the same grade, it is evident that one of them is a Rating and not a Classing. I will iilustiate by taking in inagination $\therefore$. 'ear type of Strme- Midding and "salting" or befouling it with trash till it is carried t'rereby below any of the Middling grades. Then its classification as Strict Good Ordinary would not be a Type Classing but a Class Rating. Do not let such grading confuse you. Learn the Central Types before you and all cotton so to be Classed will be found to have a close resemblance thereto.

Note: In this descriptive lesson I have kept before me : pivotal type of each grade. I have discussed them as if they were also before you, for the reason that any set of selected types of grades to be used could not vary far from those I have pictured. 


\section{CHAPTER IV.}

\section{OTHER PEN PICTURES-A DAY AT THE BOARD.}

The class is now invited to go with me, in imagination, to ? cotton warehouse in the interior where a large lot of cotton has been purchased and stored by a resident buyer. The purchaser has sold on grades the entire lot to a large firm of buyers, whose classing agent is on the ground to check out an.l assign grade values, bale by bale, to the shipment. Freshi samples have been boarded, two from each bale. representing the "show" of cotton on its respective sides. This is done for the reason that under the system of gang ginning where the cotton goes to the press from a series of several gins it is diffcult to give to each bale an initial roll of its finished cotton. If not carefully handled and watched a thin facing of the pre viously ginned bale will show to change the natural type When such a difference appears it becomes necessary to cu: deeper into the bale on both sides to ascertain its actual grading. An experienced classer will know from the arrangement of the tie buckles on the bale which is its top or its uncler sicle, but he, too, usually takes the double sample.

The owner has assorted his cotton and has selected his bes: grades for first classification. All is in readiness, and the classing begins. The owner turns to his tally book and the classer opens the double sample of the first exhibit in the arranged row. It shows to be a perfectly clean body of the whitest cotton, with a staple only a little short of an inch and cne-quarter inch in length. The fiber is fine and silken to the touch. It has been well prepared and as the classing agent closes his examination, he calls out "Fair" to be answered by the seller, "Check." The sample has an enclosed duplicate form of the tag attached to the bale. It shows the name anc: locality of the warehouse and the number and weight of the bale. The classer enters these points and the grading in his 
note book and passes to the next examination. We see that he funds several bales having a like body to the first, but some of them show a slight fleck of stain and others a mere moiety of trash. He remats that these are a little above the quarte wrate of Barely Fair and they, tom, are checked by the selle: un his original srading of Fair. The next srating is of a shorter, coarser, and less elastic staple body than the first, but it is white, ckan and well prepared. This too is checked Fair, lut the classer notes in his book, by a private mark, that it is the coarser and stronger stapled quality of that grade. Oti:ers of the same type follow, bearing similar flecks of stain and specks of trash to those of the first types graded Fair, but on account of the coarser body he declines to place them abovo the srate of:

\section{Strict Middling Fair.}

This grading is accepted by the seller. A mixed lot of botn these white stapled bodies, showing in each sample a few par. ticles of trash or a trace of early light colored foliage stain is next presented. These are, one by one, passed into the grade of Strict Middling Fair, as they have shown face, color ano staple huly higler than Fully Middling Fair, but a few classing alout linlly Jiddling Fair, or a little lower, have by agreement leen dropped to the grade of:

\section{Middling Fair.}

A line is now presented which shows specimens of both the white stapled cotton you have just seen, changed only in the matter of presenting on their faces several particles of trast of the intermediate form, a lim showins, if an occasional small stain with here and there a sleek head indicating a more marked legree of inequality. These are checked out as pirotal types of Middling Fair. A few others, not quite so good, but fatently hisher than the quarter grates of Barely Middling 
Fair, have also lecen asigned this classing. Again there is a "lay out" of specin1tus, comparing favorably in staple, body and cleanliness with the higher named types, but althous'. there is a suspicion of shate in their color. these, too, are placed in the gracle of Middling Fair. Other specimens of the last lamed cotton, slmwins a greater degree of the several kinds if impuritices named are scaled to the grate of

\section{Strict Good Middling.}

The buarl is mom cleared for a new exhibit of samples. We see the classer take from a line of samples one of a creamy white color which show a perfectly smonth face, with only a -light dotting of trash. lts staple will measure mniformly fully one and wne-einhth inches. He classes it Strict Good Middling. He must hold it here on accomnt of its color. O)thers in the line nut so woorl in character. varying in face and staple quality. muse alike. yet all a little higher than the quarter grade of Fully Good Middling, le also checks with the "wner as Strict Good Middling. I similar line of samples of a sliwhtly shaded white. embracing a like showing of variants, we see alsw that he checks wnt (n) the srarle of Strict Good Middling. Next we see him take up and open at specimen from another line. He sees that in color and staple it is the sume as the preceeding clasification. but he perceives a mark(a) increasc of Impurities. He observes two of the larger forms of tleak trash. one of the intermediate variety, and a few eonspicunus particles of pepper trash. Ile sees also a sreenish colored sced end or mote, but this he regards as inc:dental. A trace of foliage stain is observalule. (1) r a few molications of unripe cotton are present, thungh a suiticrent nnmber to point to the objection of Inequality. He clasps the sample a second time and its elasticity he finds to he standaril. He calls out the grade of 


\section{Good Middling,}

and is checked by the owner's answer, "U. K." Others m this line, of both the crean cast of color and the whiter cotton as appeared in the preceding type of Strict Good Middling, are examined. They show variants of the first type, rangmg from just below the quarter grade of Fully Good Middling above to a point just within the limits of Barely Good Middling below. All of these he and the seller place in the grade of Good Middling.

In the next line he first finds a few samples of Good Middling color and body, hut on account of increased loadings they are taken beyond the quarter grade of Barely Good Middling to the classing of

\section{Strict Middling.}

Next he examines a sample showing a degree of dark shade below that of the whiste type of Good Middling. He opens the sample and finds its face not so smooth as the previons types examined. He sees sleekheads, several pieces of trash of each of the larger forms and also a showing of pepper trash. A stain spot and a fugitive mote are to be seen. It shows a tairly uniform fiber length of one inch, and he grades it, and the line of slight variants grouped with it. Strict Middling.

\section{Middling.}

The board is now cleared and made ready for a very large array of samples. We see that in these there is a deeper or larker shade, just enough to mark a color distinction, when compared with those of the preceding lot, yet they could not properly be lescribed as falling below a semi-bright pale white cast. A single specimen being taken for examination, the classer sees that the smoothness of its face is marrerl by several pieces of broken fleak trash, and that similar pieces 
have been rebroken into finer parts and show plainly, but not to a damagingly conspicuons rlegree, in the form of pepper trash. The curling forms of immature cotton and one or more small flecks of stain are in evidence, but he sees that these have not weakened the fiber, nor established the character of inequality to a hurtful extent. He passes on in his examination till the entire lot has been classed. In all he finds some slight variations in color or impurities from that first examined, as each of the lot differs, in some respects. from all the others. You see, as he does, that the first specimen examined is approximately near a central or pivotal type, and that others are its admissable variants. As the classer calls and the owner checks, this entire lot is graded Middling. The variants have maintained their approximate relationships to the central type, by keeping within the limits of the quarter grades, Fully Middling and Barely Middling, as they show to be better or worse than the mean types.

\section{Strict Low Middling.}

The next "boarding" presents a line showing another drop in shade. Wh only one or two exceptions, none of them can be graded as high as Middling on forbilding color alone. A specimen sample shows that in addition to a darker color, it carries heavy loadings of trash. nearly or quite double that allowed on a Middiing grade, other impurities are noted in a corresponding increased degree. The suspicion of the classer is aroused, and he now begins an examination of body. He finds by breaking and measuring that the staple has a standard length of about one inch, that its inequality is not excessively great, and that the brittleness shown in hand clasp is due to overloadings of impurities. Some of the lot are brighter than the specimen first taken, yet bear the same showing of loadings. Others are slightly darker but are mucl cleaner. One by one as the lot passes the inspection of the classer, his call of Strict Low Middling is accepted by the seller. 


\section{Low Middling.}

Now a yet darker line of samples is presented. Except as to it leeper shate of duskiness and a slightly increased measwre of impurities, there is nothing to distinguish this line from the preceling for. There is, however, a greater uniformity uf colur, and coler is to be taken as a ruling characteristic of this srade. With pertect agreement. classer and seller place this lot in the wrade of Low Middling.

\section{Strict Good Ordinary.}

1 smaller lot is mow presented. He selects a sample which shows a still hower shade of color than that of the preceding exhibit. It has a rough face barly marked by stains and trasle. Its staple he examines closely, and finds it to be from seren-eighths of an inch to one inch in length. He finds its breaking strength mimpaired. but that the onjections of Inequality and impurities take it helow the Middling ararles. He classes it Strict Good Ordinary. (Ithers of the exhibit, though varying somewhat in appearance from the first, are placed in the same grate, which classing is aceepted by the seller.

\section{Gocd Ordinary.}

$\triangle$ few other samples are offered. These all alike, in ardituon to low color and trash. show signs of frost stain and other forms of affected fiber lengtls and strength. The staple body, however, is not so badly affecterl as to rednce it below the sratling of Good Ordinary. It is at classed and accepted.

\section{Storm Cotton.}

1 lot of storm cotton is now presented. Sereral samples of white standard stapled cotton are examined. They are fomm whe so haded with trash that the aralling of the cotton becomes a secondary matter. He placen them. severally, atecording to their appearance and rate value, in the grades of Strict Low Middling, Low Middling and Strict Good Ordinary. 
Inferior.

Two other samples only remain to be examined. They are very bulky, two or three times the usual size, and upon being opened they look little like a cottun exhibit. They fall far below the grading of Good Ordinary. The classer prefers not to take them, but his principals lave purchased the lot. and these two bales are a part thereof. We see a bulk composed of fibers of different length, varying from one-half inch to one inch, in part sound and strong, but with this rough presenting is a large mixture of frost stained and other unclean and damaged fiber.

Such cotton can not be graded. It can only be rated. Classer and seller agree that it would clean out at the mills about forty per cent long and strong staple, and that the remaining sixty per cent. of waste would not more than baiance in value the cost of carriage and cleaning. L pon this basis of agreement the two bales are taken at forty per cent. of their weight, and classed Good Ordinary, or the lowest commercial grade. And now the several hundred bales we have seen classed, stand lined up, each having the consignment mark of the purchaser, ready for immediate shipment. We will retire and think of the intersting work we have witnessed. 



\section{TH E}

\section{Cotton Grader}

O R

\section{How to Classify Cotton}

The above titled work is here reproduced as published in 1908. It is made a part of these lessons. The following pages, including Preface, are with only a few slight changes, identical with the original publication. The student will find all therein that may be taken as supplemental and explanatory of Pen Pictures. (Used by consent of lessee.) 


\section{PREFACE}

This liowk is intended to give a clear, comprehensive idea of the Art of Cotton Grading and Classifying. As to whether or not that work has been accomplished, he who reads it with the view of learning the Art will be rewarted. The Fiber is malle the unit of classification. Every form and variety of Fiber is described and every character of impurity that might affect it is discusserl. As these conditions are shown and explained, the sranle or class to which that particular sample or kind of cotton leelongs is given. The way of examining is made su plain that any one can understancl it.

This is the First Work of the kind ever pullisherl. IVriters, like buyers, lave seemingly considered the subject beyond the comprehension of an ordinary Farmer. It least for some reason they have acquiesced in the buyers opinion that grading and naming the price of Cotton was something of which the Farmer should exercise no primary judgment. Just a little agitation has aromsed the Farmers to a sense of their helplessness in this respect, and when they are told that it reguires, in comnection with a very short treatise on the subject, only a limited conrse of practical application in their own homes to make them fairly proficient, they will doulotess profit by the upportminty presented in this small yet complete exposition of the subject. Every farmer should know how to grade his own cotton.

The Author. 


\section{COTTON}

As to variety of subjects and quantity of matter, much has Leen written about Cotton. We have books and volumes of looks that tell us abont its antiquity, the countries where it may grow, the various kinds of Cotton grown, how and where it is manufactured and how the farmer should plant, fertilize, cultivate, gather, gin and haul it to market. We have books that tell us about machinery for manufacturing the By-Prodlicts, others full of statistical and other information, touching upon the future labor to be used in its production, or giving the great Exchange system of fixing its price. In fact. everything from the planting of the seed to the problem of transportation has been written about without limu.

\section{Not Everything.}

No; there is one thing about which, as a subject, no line has ever yet been written. If this effort shall go out to the public, it will be the First to appear as a written thesis upon the ruestion of Grading and Classifying Cotton

The farmer has been instructed in the way best to plant, cultivate and gather, but only by chance has he ever learned the difference between the grades of "l "air" and "Inferior" cotton. He has been educated to hold his cotton for a higher price, but he, the average farmer, loes not know whether he is holding "Good Middling" or "I ow ()rdinary."

It is contended that no valuable instruction of a theoretical character can be given upon the subject of Grading Cotton This is not true, only as it may mean that a thorough knowlcdge of the art nust combine the practical with the theoretical. It could as reasonably be claimed that a man who is not a college graduate does not know anything, and that no acquaintance with a subject short of a perfect knowlerlge has any real worth. The idea is absurd. If an expert classifier should say to you that a sample of cotton is of a certain grade and class 
because its staple is of a given dimension, its color is white, it feels live, flexible and elastic to the touch, its fiber is miformly good, it shows no injury from previous dampuess, it is not stained and it is comparatively clean, conld you not see these several and various points of classification as he mentioned them? Suppose next that instead of having the sample in hand, he should simply describe one of that kind, and ask you to select from a lot of cotton before you a bale that would correspond with the described grade, conld you not on first trial, perform the assigned task? Again, if instead of communicat ing with you orally, he should write out this description, could you not as well, or better, comply with his request? Could you not soon return to him and say: "Here. Mr Classifier, is your bale of Midclling Cotton"? Assuredly any intelligent man eould rothis, and what he could do in selecting this grade he could clo in selecting any other.

Ve are creatures of custom. (often men fight, bleed and die. zealously, heroically and patriotically, defending causes, which, in so far as they may know throngh persona! investigation, might prove unworthy the nane. Custom is a tyant. It is a ruler whose sway is never abated by agre. !'recedent is a despot, unfeeling, exacting and domineering. "In the way our fathers trod" is a commendable sentiment of veneration, and as a guide for our steps may have many shini.g exceptions. but, in the nain, the path which shomld have been lighted by experience remains darkened, and leack ns often over a rough and stony roarl. Who declares that the farmer wi the South, he that grows annually twenty bales of cottom, is utterly disqualified. under any character of prepatratury eftort, to grade his own cotton and know what it is worth? The answer is, "Custom." How is it, the intellinent farmer, man or boy, can not do this, when almost any city lad with a half season's warehonse experience can do it? The answer is, "Precedent lias arranged it so, and precedent must be observed." Why is it these selfisme cotton growers make no 
effort to set aside those customs and precedents which are so detrimental to their financial interests? The only answer seems to be that, though it should be quite expensive, they prefer to "Walk in the way our fathers trod." It is presump. tuously assumed by the cotton buyer, both agent and principal, that no one else connected with the transaction but the buyes is capable of judging the grade and value of the cotton to he sold and bought. This is tacitly conceded to be a proper assumption by the farmer's commercial neighbor's and frien's, and by hiur is helplessly agreed to, all because it has been a custom so to lo. So strongly has habit or precedent established itself in relation to the question of Cotton Classification, that the illea of "special professional acquirement or gi:t" seems to prevail in the face of all logic and argument to the contrary. In a conversation with an old cotton buyer frend the fact was mentioned that this Guide to Cotton Classifying was beng prepared. He expressed surprise that such a wurk should be undertaken, declaring it wholly impracticable. Fie went so far as to declare he would not be willing to go upor: record and risk his future reputation by making a written ricscription of any grade of cotton. Th hen yuestioned closely, as to why not, he could not in answer go beyond the illogical word, "umprecedented." However, he admitted that a very great deal of "valuable theoretical" information conld be given. "Theoretical" information is exactly the kind proposed to be given ,and it is offered with the honest hope that it may prove "valuable." Until the seller and the buyer can mect upon common ground, both knowing the grade and market value of the article to be sold, the man who does not know is wholly at the mercy of the man who does know.

\section{Classification Basıs.}

Cotton is classified, not according to variety, hut by Grades and Types as indicated by the staple and its condition.

Variety means kind, and its designating nane reters, prir- 
cipally, to the place, country, or part of the cruntry, where the soil and climate are adapted to the growth of that particular kind of Cotton. Ur a variety name may be sriven to an improved species.

Grade embraces staple, color, condition and cunality.

Staple is the measure of the fiber, as to whether it nay be long or short, fine ur coarse, strong or weak, with or without natural twist, miform or irregular, dead or live, elastic or brittle--the whole comprising the qualities of length and strength.

Color in sracling applies to white, as a base, and to all the regular sharles from that to the brown or Nankin. It does not include stains, fleck-marks, spots or other discolnations.

Condition follow: upon a multiplicity of cause.

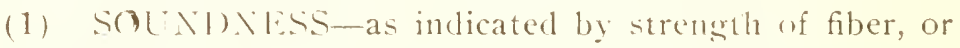
by freedom from the effects of present or previous dampness.

(2) FIR.MESS-as it may feel respemsinely live or dead to the duncin-elastic and flexible.

(3) CLE.N1, INESS-as it may have mure ur less trash or "dirt."

(4) DIS( (1), ()RATION-as from boll stain - trom dampness in seed-from possible soil stain-from the diy burr marks of late picking-from hoop stain and from onl stan.

(5) NoTlis-as from faulty ginning or from immature seed and seed ends.

(6) INEglaldTY-as from mixing dificient kinds or varieties of secil cotton.

(7) SPOTS-as from mildew or fungoid or from foliage rust-stain; and,

(8) NON-DEYELOPMENT-as shown by the lack of spiral form or natural twist in the fiber and by the unequal length and strength of the fiber resulting from a mixture of ripe, half-ripe and dead staple.

Quality is that estimate of rating which is hased upon the 
combination of staple, color and condition. Ti, tell the qualthy is wo name the srate or classification.

\section{Type.}

7 ype is more properly a manufacturing term as applied to wrades, but it is one with which the field classifier must be acquanted. It is a selected grade of cotton about which and with which other approximate grades, higher and lower, may be combined in lanmonious blending. This produces a mixture differing from all its component parts, better than the lower but not so good as the higher, and, of comse, mulike the original tyee grate. liy this method, classifying by the manufactures is reduced from the broad range uf diversified grades. to a few types which embrace the better part of these srates. The eernomy attending this order of arrangement gives, from the sereral grades selected, a miform finished product: whereas, if each were taken separately, it would, in itself, constitute a specific type. It also enables the manufacturer the more easily to supply himself with stuck, as a large bulk of cotton of any given classification is not alwars readili obtainable.

Types are male up at. or as it may be for, the mills and factories by ynalified expert cotton graders. Ilere you will find an artist who knows his profession. He does not know, necesarily, and he need not care, whether the cotton he must examine su chosely is worth in the market one dollar per pround or anly ance cent per pound, but he does knuw that the several lots or parcels of cotton he has selected, varying in weight and clasification, after being nixed and taken through all the preparatory pocesses, must proluce at combination which shall give, as a finished product. onc without noticeable difference from that resulting from a previns combination of a similar character, and, likewise, from whers he must make in future to fill a miform large order.

A knowledge of this kind has been the professional capita! 
of the field cotton buyer, as a lack of its possession by the cotton producer has long kept him on the roll of the victimized. Ye buyer understands well the art of "putting up" types, and though there could be no harm in "putting up" an honest type, it is barely fair to work the damaging "average up" plan on the farmer, when in most cases it means "average lown." Under our present system of handling cotton, the buyer is entitled to his comission or his rightful speculative profits, but the "average up" plan should be stopped by the seller till he; himself, learns how to "average up." Every farmer who grows cotton should know how to grade, classify and type or average np any assorted lot or number of bales he may offer to sell. In the sense here discussed the term type means to average, or to combine different grades for marketng at a "lump figure."

Type is also a term of distinction used by manufacturers to indicate variety. In the American mills' classification we 'have the Sea Island, some foreign, and the several Uplands varieties each constituting a type.

\section{Varieties of Cotton.}

Many exhaustive treatises have been written upon the Butany of Cotton. For a history of the plant these works are referred to, but in this effort no attempt will be made to go beyond the naming of the different foreign and home varieties and showing their textile comparison.

\section{Foreign Cottons.}

The Brown Egyptian is a very fine fibered long stapled cotton. It is used in the manufacture of high grade yarns and fabrics, and a considerable quantity is annully imported into the United States for that purpose. All other varieties of Egyptian Cutton are considered inferior.

The China and India cottons are both of very low grade. 
The China is consumed entirely at home, but India exports a large part of her raw product to Europe.

The Soutl American cottons are of many varieties. The principal two are the Brazilian and the Peruvian. The Brazilian goes clifefly to Europe, but our American manufacturers use a great deal of the Peruvian (red) in the manufacture of special lines and in the making up of types. Other varieties of the South American cotton are classed with the Mexican product and are considered unimportant both in bulk and quality.

\section{American Cotton.}

This designation applies only to the product of the United States of North America and the adjacent islands.

Sea Island is considered an American product. It is grown principally on the islands off the South Atlantic coast. All points of merit considered, it ranks highest in the grades of cotton the world over. Sea Island cotton is grown also on the nain land of Florida, Georgia and South Carolina, that of Florida being the best, but still distinguishable as a lower grade than that of the island product.

The American mainland cotton and its many classes or kinds, both native and improved, is next to be mentioned. The quantity of this general variety is greater than that produced by all other parts of the world combined, and the value set upon its middle or basic grade controls the price of cottun in all commercial quarters of the globe.

\section{Sub-Divisions.}

The most important of the several divisions or varieties of the American mainland cotton is that known as the Orleans or (iuli. These names embrace a number of included varieties, all, in the market, being understood as virtually the same. Its staple is both long and strong. measuring in 
length from one inch to one and one-half inches, and having a tensile capacity highly valued by spinners.

Products from the fields of the higher inland river valley landis of Mississippi, Louisiana, Alabana, Arkansas and Tennessete are only slightly inferion to the Orleans, but they constitute a malketal,le variety.

Texals cottun stands alone as a saparate variety. It varies irom seven-eigliths to one inch in length of staple. The prodnct of the lirazos Valley, however, ranks above this rating and is appreciated in both the home and foreign market. much above the commonly accepted Texas variety.

Lplands embraces all that yield coming from the territory mot llesignated as the home of the several special sub-varieties mentioned. Lplands cotton hats a staple from threefourths of an inch to one and onc-eighth inches in standard lensth.

\section{HOW TO CLASSIFY COTTON.}

A carefully grown, well developed, cleanly gathered, properly sinned and wrapped bale of white Lplands cotton form the basic center from which all higher or lower grades are determined. Cplands has its many "luprovel" varieties, and its sub-varieties are almost as numerous as the varied characters of the soil. the latitude and the altitude of the fieldi where they are severally wrown. Lplands, however varied is L lands and a classifier who may be able to grade one of its varuetes may as easily grade all of them.

\section{The Principle of Cotton Grading.}

In every development there is a hasic point from which growth begins. It is well known that a proper solution of any mathematical question depends upon a careful startms with its unit. As applied in mathematics so the rule must 
be made to operate in all things. If we wish to understand by investigation any given proposition, we must work out from its initial point. We must go to its base for our first and only correct comprehension of its parts. Again, there is a law governning the economy of action which prohibits the attempted performance of two different acts at one and the same time. "Do one thing and do it well, then do the second thing and do it better" is a nice old proverb. If you wisli to learn the art of grading cotton, you should take up the study alone, and let every non-essential collateral element of cotton be put aside for the time. From this preliminary it might be argued that in the cotton seed is the germ, the unit, the initial point from which to move out in the start to study cotton. I have before told you that volumes and volumes have been written upon cotton with our subject Cotton Grading, left ont. These writers begin with the seed and have taken you everywhere else but to a knowledge of classifying the staple about which, otherwise, they have written so much.

Our subject, Cotton Grading, has its unit, an initial point, a starting place, that is wholly and entirely its own. If from a bale, or any large bulk of cotton, you should take away, part by part, the smallest quantity you could separate from the general mass, in the course of time, though it should be a long time, you woulu come to a last small part, a little filament, and this is your Cotton Grading Unit. It is a simpic.

\section{Fiber.}

Jo learn to classify cotton here your study begins. You must know all about the single fiber and its combinations with other fibers of the same or of different kincls. Desprse not the study of small things if you would undertake the consideration of the cotton fiber, for you are to take only one and it is so small that it would require one hundred and forty millions like it to weigh one pound. 
The cotton fiber casually observed presents a deceptive appearance. Viewed thus it looks to be a small. long, solid and perfectly round body, but upon closer observation it shows itself as a narrow flattened tube, twisted in form, and in tnis respect, resembling sumewhit a spirally curled hair. The fiber has its tip extremity closed but its base is fastened like a mouth to its mother seed, from which it feeds itself by a capllary process to maturity. Fiber does not taper in form. It has the same diameter in all the parts of its lengtli. It lias a Iarge or small cavity, and is flat, or retains more nearly its dpparent cylindrucal form, according to its full or its imperfect development. A perfect fiber is covered by a thin clinging dustlike membrane, called by botanists the "cuticula" or skin. This covering sometimes goes with the fiber through the factory into yarns or other products, but oftener it disappears in the form of gin dust or mill dust. It is comparatively weightless and neither adds to nor detracts from the value of the staple.

Fiber may be fully developed and still be short or long according to its parent variety. The range of length is from one-half inch to two inches. This measure of fiber length is designated its staple and is the first item to be considered in crading or assigning value. Other items, however, relating to the fiber construction are to be reckoned. They are the core (1) diameter and their strength or tensile power of resistance.

The following shows the relative diameter, length, and strength of the fiber helonging to the several varieties presenterl:

length Inches

Sea Island

Orleans ............ 1.02

Texas .............. 1.00

Uplands ..............93

Egyptian $\ldots \ldots \ldots \ldots . . .41$

Indian $\ldots \ldots \ldots \ldots \ldots . .89$
Diamerer in. Breakit getrain,

.000640

83.9

.000775

147.7

.000765

109.5

.000763

104.5

.000665

127.2

.000894

160.7 
This table is given to show that the fiber with the greatest diameter is the strongest and that usually the coarser grades of fiber belong to the shorter staples.

The measure of tension or breaking strain of a single fiber is estimated by spinners to be from five to ten grams or from eighty to one hundred and sixty grains, or an average of about fifty fibers to sustain a pound.

\section{A Closer Study of the Fiber.}

Again let the fact be emphasized that the cotton classifier must be perfectly familiar with the unit of classification. Impurities found in cotton are to him a secondary matter. They are usually easily traced and their causes located. Never let any appearance or condition of a cotton sample take you away from a study of the fiber as the part most affected by that condition.

After the cotton boll fully matures and opens, a few days of exposure to air and sunlight are beneficial, in the way of giving to the slower maturing parts of the pod nature development, and to the whole spiral individuality of fiber. But if left longer than this. exposed to heat and air, the fiber will tend to become harsh and brittle. and the longer so left the more perceptible these injuries become. Besides, if strong winds prevail. dust and sand will be blown into the open cotton. and if it should rain much, water stain will follow.

\section{Natural Twist.}

The Natural twist of the cotton fiber varies from about two hundred turns to the inch in good grade Uplands to three hundred turns per inch or more in the best Sea lsland product. In connection with its length the value of the fiber hinges upon this quality, as in manufacturing the joining process with other fibers depends upon this as an interlocking principle. Manufacturers use the microscope to ascertain ex- 
act spiral character, but this does not imply that the ordinary wrading classifier, whth his natural vision, holding a sample section in hand, cumbl not determine quite well enough for practical purposes the presence or absence of this guality, just in the same way he would form conclusive opinion as to lensth, strength, and other special characteristics of the firer murler examination. Natural Twist is not to be confonnded with the Elastic Twist of a live healthy fiber. It is the vital foree, hemerer, of Natural Twist that gives the kinky form of Elastic Twist.

\section{Unripe Fibers.}

In every sample of cotton. from the highest to the lowest wrate bali-ripe and torally dead filers may be fomml. Nature in matry instancen mat le able to parate its lines of perfection, but as small a puantity as a single pound of perfectly develofeel and matured lint colton is not included on its list. In at single pound wi conton there are about one hundred and forty million separate and distinct developments of independcult fiber. In a hate uf cotton there are about five liundred

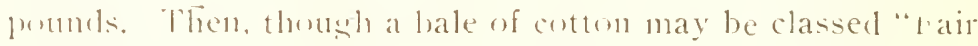
or "Extra" or "liond," terms representing the highest classification of the learling the varieties. We are not to look for a total absence of in! w the lefects upon which such classificattion is based. Is to latif-ripe and dead fibers, their presence is natural. Lifigh ma! fall npun the learing plant after onehalf the bolls hate matured in a healthful form. In like manner the bruising of heaking of limbs on a part of the stalk would cause a similar order of rariable ripening. Fibers in the same boll do not all mature simultanenusly, yet the boll "pens to accommorlate the ripe and presents the nuripe to the picker in its meleveloped state. Therefore, half-ripe and dead fibers are to be lowked for naturally in every sample of cotton. (1) comrse, if they shumd form tow sreat a pereentage of the seneral bulk, which is sometimes the case, a corresponding 
lower estimate should be made of the grade, l,ut you should know that "Dead Cotton" is a favorite term used by unscrupulous buyers who seek to undergrade. Ne do not need the microscope to detect the presence of half-ripe or dearl fibers in a specimen sample. The half-ripe is shorter than the mature staple and has less spiral turns in proportion to its length. The lead fiber is like a lifeless parasite windingaround and clinging to the mature and the half-ripe fibers. A careful examination, suggested by lacking elasticity and flexibility, will show the grader these fualities. If only the normal quantity is found they may be passed monoticed, but if they appear in exaggerated form the grade is to be correspondingly lowered.

\section{Broken Fiber.}

The inferior or unfit condition of a gin, or the rapiditity of its revolution causes the saw-gin to double cut the fiber, taking it from the seed in two sections or leaving a part of the fiber with the seed. This dues not uccur with the use of the roller gin, used for long staple cotton, but sometimes, with it, there is a rude rupture of the fiber noticeable. With a sawgin this defect would almost certainly go through the entire bale under examination, and perhaps through many others. It is easily discorered and detracts considerably from the otlyerwise good grade of cotton.

\section{Stained Fiber.}

One drop of ink in a glass of clear water utterly mars a purity of its appearance. A less proportionate part of stained cotton in any sized sample would indicate a greater apparent departure from perfection. One stained fiber in a small pinch of cottun, pulled through the fingers of the examiner shows like a multitude of wriggling rainbows circling a section of clearly outlined horizon. Stains, whether important or unim- 
purtant, are good capital for the decrying buyer, who would take advantage, in a purchase from the uniformed producer. Under the head of "Conditions," on a precelling page, are enumerated and named the different kinds of lint-stain, considered by the field buyer, in his cleals with the farmer and th country merchant. Here I shall refer to the commercial stan only.

\section{Boll Stain.}

Boll Stain is cansed by water that has entered a partly opened boll and saturated the inner pod. The coloring matter from the inner membrane is washed into the general lower borly of the pod and gives to it a red or brown shade. This is considered of not much importance, as in the manufacturing process of dyeing and sizing such stains would disappear.

\section{Hoop Stain.}

Hoop Stain is nothing more or less than iron band rust and really, in itself, amounts to only the loss of a few ounces of cotton to the bale. However, it suggests a character of neglect or want of care pointing to other impurities, and forms of clamage, and furnishes a good excuse or cause fur lowering a grade.

\section{Oil Stain.}

Oil Stain is cansed by the crushng of the seed in the gin; the exuding oil giving to the fiber a yellowish color. If this staining should be general throughout the parts of a bale of cotton its value would be much reduced. Its waxy and gluelike nature retards the process of carding and spinning, and such cotton is often wholly rejected by spinners. A second kind of oil stain is only a probable stain manifesting its almost certain future appearance in the form of immature seed in the meshes of baled cotton. Separation at the mills is a task ton 
difficult to be undertaken, and if left in, they are crushed by the mill machinery and regular oil stain is the result. "Seedect lint," as it is called and oil stained cotton are to be graded alike

\section{Fungoid Stain.}

Fungoid Stain is but another name for mildewed cotton. If may follow as a result from a number of causes. It ranks with "Damaged Cotton," and there is no special grade to which it may be assigned.

\section{Fiber in Bulk.}

Fiber in bulk is cotton lint in large or small quantity, or a mass of fibers taken in aggregate form. In treating fiber in bulk, the single fiber is supposed to have passed examination as the basis of staple, or as it is to be considered the representative of the general class of fibers forming the larger mass to be graded as a whole. Cleanliness and soundness are now the points to be considered.

\section{Broken Leaves.}

The leaves of the cotton plant, and sometimes bearded or hard stemmed grasses in badly cultivated fields, are natural factors in reducing the variety and grade of cotton. A dry leaf in close proximity to the open boll is very frequently included in the hand grasp of the hurrying picker. If it is not removed, it goes with the mass of seed cotton through the gin and is broken or cut into small fragments. The smaller these particles of leaf are made by the gin, the more thoroughly they becorne mixed with the fiber, and the more difficult they are to remove in the preparatory processes at the mills. The larger pieces may fall out of their own weight, and on this account are not considered so injurious to the grade, but the smaller ones remain, and, if very fine, are considered a clinging and 
inseparable impurity. The skeleton of the leaf, too, a sticklike tissue, often becomes a part of the foreign mass. It is classed "inseparable," and is, therefore, correspondingly objectionable. These impurities, as you see, are themselves to be sraded. If the cotton sample shows leaf trash in large pieces without the stem or skeleton accompaniment, its grade is not hadly affected, but, if the trash shows in the form of small, pepper-like particles, or has the stick cuttings, a caretul grader will mark it down.

\section{Broken Seeds.}

This constitutes what is known as one of the "Heavy Impurities" of cotton. Broken seeds are usually covered witli lint or fiber ends, and these becoming interlocked with other fibers are difficult to remove. In Grading, these impurities are called "Shell" or "Bearded Motes." The surplus parts of body or fatty ends of seed are uften cut into the lint roll by close ginning. "These pieces are also called "shell," and rank with heavy impurities. Cotton affected by these impurities is to be graded with the lower type of "liroken Leaf" cotton.

(Note if the fungus end above mentioned shomld carry a part of the main body of the seed. In such case, oil stain would result. )

\section{Sand and Soil.}

The winds sometimes fill, or, as it is termed, "luad," open cotton in the burr with sand, and again, often it is blown or knocked out upon the gromnd and becomes impregnated, more or less, with sand and other earth matter. This affects only the weight of the cotton and not its quality, unless soil stain or mildew should follow. Spimers, however, claim that the extra frictional wear to machinery and danger incurred from fire render it less desirable, and, therefore, it is bromght to a lower grade. 


\section{Dampness.}

Dampness or moisture is not to be considered an impurity, only as it may become the possible producing agent of mildew or rot. To form these there must be a meeting of the damp part of a bale of cotton with the air from without. Such meeting would afford the needed means of evaporation, and thereby the cause of deciay or rot would, in the main, be removed. Cotton dry enough to gin, if immediately compressed, would be safe from serious harm to be occasioned by dampness. Even cottun "wet down" in the compressing or baling process wonld suffer little injury therefrom, as evaporation would be very rapid. If, however, the place of storage should be damp, or if by constant exposure to water and exterior dampness, evaporation should be prevented, mildew would follow and rot would be the result. Cotton is a great absurbent. A bale of cotum placed over an evaporating pool will drink in dampness like a thirsty animal drinking water. Continued absorption with the avenues of evaporation closed would soon reduce the fiber and deaden its twist. With it. quality of elasticity thus destroyed it is in the first stage of decomposition.

In grading a bale of damp cotton, if the moisture is found to be only near the surface, produce a specimen sample below the damp part and classify as if no water had been observed In weighing, the proper deduction for water.weight can be made. If the dampuess should extend into the interior of the bale, the classifier is placed in a dilemma. Excessive dampness disturbs normal elasticity and he will be able to judge of this quality only as a collateral adjunct of the length ancl strength of the staple under examination. He will be able easily to know whether this dampness is new or fresh or whether it is an old water sob. If the latter, the form and strength of the staple, besides the changes before mentioned. will show rank abnormal differences in fibers of apparently even development. Iarts of the same staple will show differ- 
ent degrees of elasticity, and an unmistakeable odor of mustiness will manifest itself. Cotton in this condition, no matter what it once may have been, is now to be graded "Inferior." If, on the contrary the bale should appear to be generally damp, and otherwise sound, its grade is not affected and a deduction for water-weight from the bulk weight of the bale is all that need be clone in fairness to seller and buyer.

\section{Structural Composition.}

In a work on Crading and Classifying it is not necessary to go into the "Chemistry" of the cotton staple. However, as the laws of Fermentation, Decomposition, Fungi, etc., operate with more or less force according to the physical stability of the substance to be acted on, any one desiring thus further to investigate is referred to chemistry as applied to these questions, and in that connection, the following structural analys : of cotton is given:

Fiber 83.71 per cent

Water

$6.7 t$ per cent.

Free Nitrogen ...................

5.79 per cent.

Ash

1.65 per cent.

Protein

1.50 per cent.

Fat 61 per cent.

100.

Porusity is a general property of matter, lont the surface pores if a simsle fiber of cotton are too nearly allied in magnitude to the atomic alature of their surroundings to give passage way to the combined elements composing water. Hence moisture of cotton is due wholly to fiber-layer and capillary avenues of ingress.

\section{Dryness.}

Tn connection with Dampness is to be consideted a principle 
of Dryness, that affects the worth of cotton. A sample of cotton of average high grade, in its normal state, contains nearly seven per cent. water. Immerse it in a vessel of water till it becomes thoroughly saturated, then expose it to the air and sun for a few hours and it would show only its normal quantity or part of water. Subject it next to a heating process. Confine it in a bake-oven or other drying place till, as nearly as possible all moisture is driven out, expose it again to the air and from that element it would soon absorb moisture enough to have its original normal quantity. It is this quality of dampness that enables the classifier to judge, through its character of elasticity and flexibility, the presence or absence of the necessary vitality in a sample under examination. A healthful weil developed capillary state of the staple gives a normal condition of dampness. This in turn through the elasticity and flexibility of a sample containing it proves and shows the origin of its presence.

\section{Flexibility.}

As a rule flexibility indicates strength of fiber, though short, coarse and strong staples are rather more harsh than flexible. A sample of the latter kind, in response to the touch or clasp of the hand, will show sufficient capillary (cavity) force to indicate its right position in the line of grades. If from any cause a sample staple should show a quality of dryness below that of the normally damp stage, it would be indicated by a harsh, brittle yielding to the touch, and upon closer examination it would be found wanting in some of the characteristic essential points of good grade.

\section{Grades of Cotton.}

In an American cotton crop of twelve million bales, if graded by the bale, it may be truthfully asserted that twelve million different and varying grades would be found. In otl er words, no two bales could be found that would sample 
"through and through" or "out and out" in exact likeness. Notwithstanding this fact, there might be found, say, one-third of this number of bales that would be so nearly alike as to be classed toget'her as one type or grade. Another small fractional lot, better or worse, higher or lower, finer or coarser, might be found that could be placed in another grade. And so on, another fractional part of the twelve million bales might Le found having a general bulk likeness and similar grade ciuality, till the whole could be enbraced in about twenty of these factional divisional parts. These twenty or more parts might again be sub-grouped into seven or eight distinct qua!ity divisions, designated "Full Grades," with which higher or lower approximately similar grades may be typed, to compose a bulk lot of cotton of a required given classification. These approximates are designated "Half" and "Quarter" grarles

\section{The American Exchange Market.}

As an American proposition, both the classification of cotton and the price to be paid for it are regulated by a class who have $n$ interest, whatever, either in its production or its manufacture. We have two great commercial or market "Exchanges," located respectively in New York and New Orleans. Seats in these "Exchanges" are of high commercial value, and are of a linited number. The membership composing them is supposed to be "strticly" American. but it may l,e remarked, soto voce, that the supposition is "strictly" a supposition. From these places the men who have no part in producing, hauling or manufacturing cotton, designate the terms by which its differing grades shall be known, and dictatorially declare what the market price shall be. This is only another way of showing our Anerican disposition to bow to "custom," respect established "precedents," and "walk in the way our fathers trod." But the right or wronc uf this custom is not a matter to be discussed here. 


\section{Grade Classification.}

According to American Classification there are seven fill grades of the mainland varieties with which, however, neither the Florida now the Cieoreria and Sonth Carulina loner or Sea lsland staples are to be included. These seven wrates are: Fair, Middling Fair, Good Middling, Middling, Low Middling, Good Ordinary and Ordinary. Fair is the lishest and best srade and, therefore, there can be no half or quarter grades above it, but, leseculing, all other grades have half or quarter srades both abure and below them. The complete table of American grales used until recently by the commercial world is as follows:

(1) FAIR, Barely Fair, Strict Middling Fair and Fully Middling Fair.

(2) MIDDLING FAIR, Barely Middling Fair, Strict Good Middling and Fully Good Middling.

(3) GOOD MIDDLING, Barely Good Middling, Strict Middling and Fully Middling.

(4) MIDDLING, Barely Middling, Strict Low Middling and Fully Low Middling.

(5) LOW MIDDLING, Barely Low Middling. Strict Good Ordinary and Fully Good Ordinary.

(6) GOOD ORDINARY, Barely Good Ordinary and Strict Ordinary.

(7) ORDINARY, Low Ordinary and Inferior.

This system, or catalog, of classifying terms is as old alm st as the American entton market itself. When the Inericats cotton exchanges first were established, about thirty-five vears ago, they arlopterl and used the old classifying terms. But within recent years they have dropped out the five grates belww Good Ordinary, aurl have substituted w arleded thirteen new terms. These added terms are: (1) Strict Good Middling Tinged. (2) Good Middling Tinged. (3) Strict Middling 
Tinged. (4) Middling Tinged- (5) Strict Low Middling Tinged. (6) Low Middling Tinged. (7) Strict Good Ordinary Tinged. (8) Fully Middling Stained. (9) Middling Stained. (10) Barely Middling Stained. (11) Strict Low Middling Stained. (12)Fully Low Middling Stained, and (13) Low Middling Stained. Middling is still made the basis of value, and Good Middling Tinged is placed on a par with it. The regular classification in its revised form, showing the 1907-1908 variation of values is given on the next page. The difference in value therein quoted is rather more basic than arbitrary, and is changed as the demand may increase for a specific type of cotton.

Note: the given print referred to above is not much at variance with the present differences. The matter is therefore kept before you only as a guide to the method of determining grade valuations. 
New York Differences in Gradc.

Cents.

Fair ............................ 1.75

Strict Middling Fair .................. 1.50

Middling Fair ....................... 1.25

Larely Middling Fair . . . . . . . . . . . . . . 1.00

Strict Good Middling ................... $\quad .75$

fiully Good Middling . . . . . . . . . . . . . . . .

Good Middling ....................... .50

liarely Good Middling ........................

Strict Middling ..................... $\quad .25$

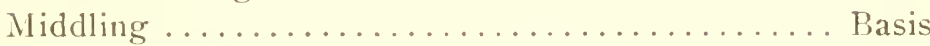

Strict Low Middling ................ . 30 off

rivlly Low Middling ................... .6. .65

Low Middling ...................... 1.00

Barely Low Middling ................... 1.25

Strict Good Ordinary ..................... 1.50

Fully Good Ordinary ................... 1.75

Good Ordinary ....................... 2.00 “

Strict Good Middling Tingerl .............. .35 on

Good Middling Tinged ................ Value of Mia.

Strict Middling Tinged ................. .20 off

Middling Tinged ...................... . .30 "

Strict Low Middling Tinged ............... . 1.00 “

Low Middling Tinged ................... 1.50 "

Strict Good Ordinary Tinged . . . . . . . . . .... 2.00 “

Fully Middling Stained ................ 1.00 "

Middling Stained ..................... 1.25 "

Barely Middling Stained ................ 1.75 “

Strict Low Middling Stained .............. 2.25 "

Fully Low Middling Stained .............. 2.62

Low Middling Stained ................. 3.00 " 


\section{Tinge.}

The terne "linge" or "Tinged" an applied in this classification refers to natural color only, and wot to any stain or dye form extrancous cantses. The eolor of cotton is strongly matked hy the character of the solil upon whell it is produced. l)ing! staty. creatn, yellowish brown and wher shades are (a)mumen degattures from white, which is the color quality of the best srater.

\section{Sea Island Cotton.}

Sea f sland coston is classed nu only two (American) varieties and seven srades. The varieties are the lsland proper and the Mainland. A ristinction between the Florida product and that of (ienryid and Carolina is sometimes made. This would Eve a thirl variety. The grades are: Extra Fine. Fine. Medilum Fine, Good Medium, Medium, Common and Ordinary.

Egyptian and ludia cotton, and the South American product have cach a large number of varieties, but a limited order "if arade classifications. In this work it is not at all necessary tu) (purte these points specifically ats its scope is intended to cmbrace only the American classification.

\section{Grading and Light.}

Lgain we are brought to the unit of classification, the fiber. Ti, julge poperly the character of a sample staple, we must lee able to see it under favorable comblitims. Sunce it is a relicetion of the direct ray of light falling upon an object thit krings it to view, the best view is to be obtained by making the line of vision and the line of direct ray to coincinle. That is, in liomely parlance, we must look at an object from the direction the light comes. In this, the latitule of the Imerican cottonbelt, the sum in his path of apparent travel from east to west, heds an inclining or direct ray from the south. In the open, that is. at the wagon or on the street, the lunlk of the cotton 
crop is first sampled. Here the experienced buyer, if the day is cloudless, will turn his back to the sum, and proceed with his inspection. But if the day should be partly cloudy, so that direct rays from the sun would be obstructed, he would turn from the sun to the largest belt of open skylight presented. to obtain its reflected rays as a best light for examination. On the outside, however, the eye of the experienced or inexpes icncer examiner would doubtless accommodate itself to the best light conditions, theonly difference being that the exaniner with experience would take his pusition naturally and quickly, whereas the other might movein the line of experiment. Off the street-within walls or under shelter-with samples on the boarl, the item of good light is all important. Light openings almitting direct rays from the sonth southeast or southwest, are usually too beaming. Similar objection may be raised to the werlead light, on aceount of its "borrowed" wlare. The bes ight, then, is that to be reflected on a bright day from an open clear expanse of northern skylight. This afforls a soft mellow light, such as enables the examiner to discern the shades of color.

\section{Color.}

The highest grate of cotton is naturally bleached and must he perfectly white. Cotton having a corresponding quality of staple, cleanliness, Hexibility and general purity, but showing a gray, cream, or brownish cast, would be considered "off color," or, as it is termed in the newer classification, "Tinged." Cotton that is tinged cannot be classed with any one of the highest four grades-that is, with Fair. Strict Middling Fair, Middling Fair and Barely Middling Fair. The name, "Fair," being given to these grades, as we may understand, precludes the possibility of "Tinge." Cottons of equivalent grade in every particular, except color, vary about one-half cent per. pound in favor of the white grade. In the "Grade List" issucd by the New York Cotton Exchange September, 1907. Good Middling was rated one-half cent higher than Middling. On 
the same list Good Middling Tinged is given the same value as Middling Untinged. This order of difference in valne prevails throughout the list and is to be accepted as a law which fixes the color variation of value at about one half cent per pound.

\section{Vision and Touch. .}

Vision and touch are the co-operative agents in the work of classification. The eye and the hand move in harmony to a quick and practical decision. A representative sample is procured by the examiner. He plucks from the larger parcel a smaller quantity in a seemingly careless manner, yet he gives the very closest observation to the particles of fiber as they may kink, twist about, cling together, and slow such other characteristic resistance or yielding to separation as would indicate certain points of grade. He compresses the detached smaller part in his single hand, noting the easy pliability, velvety softness, naturally live moist touch, or, as it may be their opposites, harshness, dryness and brittleness, judging in a moment the presence or absence of that flexibility, elasticity and responsiveness which give vigor and strength to the staple body. He turns again to the staple. With thumb and finger he separates or pulls apart a smaller purtion that he may see the length of the fiber. and judge by its resistance to separation its general quality of strength. He will note that the fiber is of muiform length or not: that it is coarse or fine, that the layers lie in parallet line or departing angle, the presence or absence of gin eut and dead fibers, and particularly will he note the spirality of movement and the quick or slow action of the ends of the separated fibers, as they coil and move back to the bulk which has retained them. Again he will turn to the general sample. Of its dampuess and soundness he has alrearly judged. He looks for impurities. He sees broken leaves, sticks, shells and stains. or does not see them. He may find much foreign substance and impurity. and he may find only the few that are termed natural. In the 
meantime color has been determined, and the whole question of classifying that grade has been settled.

In the matter of Grading cotton the governing principle is the character of the staple. With good vision and touch it is easy to know its quality. Then, as a rule, first locate the exact Grade of the staple, and place it in that classification regardless of whatever defects it may carry. Next, proceed to list its impurities. If it has no impurities or defects, it belongs in the grade assigned to its staple, but if it has, note them, one by one, and reduce the classification accordingly.

\section{Where the Farmer Stands.}

You will observe that under the present classification the white grades range from "Fair," the highest, to "Good Ordinary," the lowest, embracing in number seventeen grades. The quoted difference in value of the extrense grades is three and three-quarters cents, or an average of nearly one-quarter of a cent per grade. Grading cotton, in so far as the farmer is concerned, is either a ridiculous farce, or cotton buyers, as a class, are superior morally to ordinary humanity. There are doubtless many honest grading buyers, but many does not mean all by a great number. The opportunity is afforded, and the temptation is great. The farmer does not know, and if he is willing to prove his satisfaction with a "top of the market" sale by "setting up" dinner to the buyer after the transaction, all conscience twinges are alleviated. Let us take a good "Uplands" producing county in any one of the states and from September and October clean pickings of well matured goci stapled white cotton suppose 2,000 bales shoulil be marketed. According to these conditions 1,500 of these bales wntht to be yraded "Strict Good Mirldling," some of them higher. The chance would be, however, that not one in the entire lot would be graded above "Middling" and many of them below that grade. Middling is the basis of the market quotation, and the farmer who gets the highest quoted price and returns to 
lis neighbors with the boast, "I got the top of the market for the most of mine," is the victim. In such a case the actual loss to this one county of cotton growers would exceed $\$ 5,000$. let, year after year it is clone, and thus it has become a custom. While dignesing in this line it is proper to state that the spinner-the manufacturer-is not a party to this one-sided ical. When the cotton in presented to him every srade and Iye is priced according to its value-no nore and no less. In this latter transaction all parties are eipually well informed. But the poor farmer! Where was he?. In all his long life he has not had even one little short week to give to

\section{A Study of Classification.}

Keeping in mind the fact that perfect staple and absolute treedom from impurities are not to be expected in the highest typed bale of cotton, we have none the less a standard highest grade. From this wrade to the basis, the middle or medium grade between the highest and the luwest, including "Strict Good Middling Tinged," there are ten steps of hescent. If we should take a bale of our best stapled and cleanest white cotton and grade it "Fair," there must be some falling off either in quality of staple or character of purity, or both, to make the tirst descending step to "Strict Middling Fair." There might. not appear any adilitional impurity and the staple might be as good, yet different, and the grade is not the same. The long fibered more fragile lut finer filament would take precedence wer the shorter, coarser and strunger staple with which it would be compared. As we wuld come down the line, at each step we shoulth find changes in the classification occurring from difference in length and strength, lack of uniformity and other freviously mentioned inequalities of the staple.

\section{The Basis.}

"Middling," the medium or midlle quality between "Fair" and "Ordinary," is the basis of classification. Given a sample of white, firm elastic and flexille lulk fiber having staple of 
mniform measure from above three-fourths of an inch to one incli or more in length, with a minimum showing of broken leaf, and withont stain or any of the heary impurities of shell. motes, etc., and we should have an accepted grade of "Mir. dling." (O)serve there is a difference between "broken" leaf and "peppered" leaf. The latter in its pulverized form is considcred a very objectionable impurity, as previously explained. No sample carrying powered leaf in quantity. or stem trasis could be classed "Niddling."

All classifications, higher than Middling, are -mpposed to be unaffected by any slight impurities they may carry. But from "Middling" through the descending grades impurities are an important consideration. Staple still holds its priority. But even a good staple loses its finer character when associated with impurities. The (puality of the staple falls wif. or the im1nrities increase, or botl, in the old classification, from "Midulling' 'to "Interior." "Inferior" grades are usually from late pickings of short-developed or half-open frost bitten bolls. The staple is of the lowest type, and the fiber is nearly alvays stained. "Inferior" has its descending grades through a varying line from bad to worse. known as "Dog-tai!s."

All strict commercial classification lies between the grades of from "Fair" to "Good Urdinary." These represent the extreme variations in value of abont four cents. Below the srade of Ordinary, "Tinge," or the natural color of the cotton, coes not affect its grade. From this pont it is purcly a question of staple and impurity. In this matter, if the staple is comparatively good or bad the accompanying impurities would sovern its valuation. The whole list of impurities has been given on a preceding page, as well as their respective degrees of damaging character. A careful study of the question of Impurities should be made. "The last of the crop," is supposced to be gradeless, but not so; it is only gradeless as it affords the buyer an opportunity to place his knowledge against the inexperience of the seller. IT'here one knows and the 
wher guesses, the guesser los es. The shrewd buyer not only grades this kind of cotton, but he also grades the man who oftors it for sale. That is, he sizes up the one and undergrades the other, much to his own satisfaction and profit.

\section{Codes.}

We have only a few very large cotton firms who buy directly from the producer, yet the whole field is covered by them. Instead of the usual terms of commercial classification, each of these firms lias a "Code" made up of letters or figures to represent the different classifications. These "Codes" are t:sed only in one way. and that is in the deal between these same buyers. w their agents. and the farmers or producers. When the mm is marle by them to the regutar market these "Code" classifications are dropreel, and the regular market terms are employed. Imagine the blank look that would shade the face of any regular market buyer if you should offer him a lot of cotton and tell him that it ought to class all around, fours or fives or lis or Ds. He would 110 more understand you than if you were to address him in Chinese. These "Codes" are admitted to be variable; that is, subject to change, as to the precise grades represented at all times. In several of the states. the Sta te of Ceorgia for instance, the arbitrary "Code" of one firm of cotton buyers is the only classification known.

Granting the probability that no imposition has been practiced through this method of grading, still a uniform basis of classification, understood by all, would be better. Then again, If, say, "fours" in Alabama is not "fours" in South Carolina, what would be "fours" in Georgia? If I should fix a "Code" grading "Fours" as Middling and you shoukd so undesrtand it, and, later for my convenience, I should change "Fours" to "Good Middling," to say the least, you would not have a clear conception of the market grades. It is generally conceded that a uniform universally accepted system of grading by number would be better than the present, wut until such time as this may be clone, let us cling to the old system. In the present 
system of private Codes in use the numbers range from one tor "Fair" to four for "Middling," 'and eights and tens for the ordinary and inferior grades. The numbers employed, however, run much higher, as the lower grades are to be designated.

\section{A Quotation.}

Charles William Burkett, Professor of Agriculture in the State College of North Carolina, in his work entitled "Cotton," published in 1906, comments on the respective situations of producer and buyer as follows:

"Ordinarily the judgment rests solely with the buyer. He classes fiber as he thinks it should be classed, or as he chooses tu class it, and offers a market price for that grade of cotton. You can readily see that where only a single buyer is present, and especially if that one be unscrupulous to some degree, a considerable loss may come to the producer and a correspondmg gain to the buyer. Naturally there are tricks in buying cotton as there are tricks in other trades, and honesty and business integrity find recognition in the cotton market as they do elsewhere in life.

"The most satisfactory selling is done where several buyers are on hand, and this competition, as a rule, means the highest price will be offered. Of course even in this case buyers may join hands and one do the most of the buying one day. another a second day, and so on, each taking his turn and getting his cotton at the lowest price. But the daily paper now gives the farmer the prices in the leading markets of the world. and with the railways making transportation to better markets easy, he usually secures what the product is worth, or at least the market value of the grade in which it is classedl."

The "But" above, referring to daily papers and railway. loses all its force in the concluding words of the paragraph. which are, "Or at least the market value of the grade in which it is classed." Yes, classed by the buyer and not the seller. 


\section{TYPE EXAMINATION-SAMPLING}

A sample of cotton is, or should be, a fair representative type of the bulk or bale from which it is taken. It should be procured from a part of the bale that has not been affected by contact with the compressing machinery; that is, away from the ends or sides of the bale, and from beneath the outer layers composing the bulk. A good sample shonld weigh about three ounces. The first work of the examiner is to determine the body quality of the type in hand; that is, to learn, through its showing of elasticity, flexibility and yielding to the torch, whether it belongs to the higher, the middle or the lower grades. This he may do almost unconscionsly, as he grasps the sample in first clasp of hand, or later separates a part of it into staple length and then "opens up" the layers to lowk for such impurities as may be fomd affecting the budy as it nas presented itself to him.

In the examination of a type, as a rule, its high or low grade is indicated by the smooth or rough character of its face. If the cotton is of a low grade the face of the type will be naturally rough. (In the contrary, high grates show a smooth face. There is a lacking smouthness, however, indicated by ba: "preparation" that should not affect to any wreat extent the grade uf an wherwise smoothe type.

This is caused by ginning damp cotton or compressing it while in a damp state. In such cases the fibers are often massed or rolled together. The staple is not injured thereby. except in appearance, but bad ginning thus affecting the face uf a type would cause it to be dropped at least a half grade below its stanlard worth. In the fair grades the fibers lic low. close together and grve the face of the type a clean and perfectly smooth appearance, except, as stated, in the case of gin roll, which may show in the form of snall rupe like ridges.

Poth the hand and the eye are used to determine smootrness. The sense of touch co-operates with that of rision, and 
whatever the decision may be, it should always follow as a result of the joint action of these agencies. As the grades descend the faces of their various types grow rougher. Brittle. ness, showing the lower character of staple, manifests itself in upturned fiber ends, small opening lines, and irregular swellings and depressions. Dead and half-ripe fibers, white an! sleek, show themselves like little bow-backed worms or curl ing blisters. Trash adds its quota, both in appearance and to the touch. Stains show their natural tendency to kink the fibers carying them. These, including motes, neps, shell, seed-ends and every uther kind of impurity-all-as they may show themselves in small or great degree in the various type faces, show at the same time the smoothe or rough face of the type affected by then. Then after a general estimate of the body of the type. made in the minuer suggested, proceed to pass upon its quality of smoothness, and your decision of grade thus found is now to be verified or corrected by a closer inspection made through "opening up."

Types or samples of cotton lie in folds or layers. As they "open up" the true type of cotton is revealed. As the parts are separated every impurity seems to stand up for recognition. P'articles of trash, stains, sleekheads, and ot'her forms of perished or immature fiber. including the knotty burr-sink: motes, shell, seed ends and other indications of bad ginning, if they slould be present, each and all appear fully conspicnous as the bat or layer "opens up." Color also is scen anew. and an estimate of the finish or smoothness is again taken. Three "opens" of a sample or type are usually made by the classer and "How lt Opens" is the basis of lis grading esi $\mathrm{i}$. $111 \mathrm{atc}$.

\section{GRADE NOTES.}

Fair.

This is the best grade of the several varieties of American 
short-stapled cotton. It is commercially described as being purely white with staple, if coarse and short, ranging from seven-eighths of an inch to one inch in length; or, if fine and long, from one inch to one and one-quarter inches in lengtl. It should have in either case natural twist, denoting mature development, or so nearly mature that but few dead and halfripe fibers wonld appear to mar the face of the type and change its character of perfect smoothness. This grade is commercially supposed to be absolutely free from impurities, yet, as "purity" in cotton-grading is only a "nearest pure," it may carry a bare trace of the slishter offsets to perfect cleanliness. If more than a merely pereeptible trace is shown, of course, the grade should he scaled, at it in termed, that is, dropped to a lower classing. This scaling hat two points of limit. If the type is placed upon the market upon the basis of a single bale or small lut sale any descent from Fair would necessarily go to the next regular commercial grade, Strict Midlling fair. but the same cotton, while it could not be graded Fair, might so nearly approach that grade that it would be better even than Barely Fair. In which case, if marketed with a type lot of cotton centering near any given grade, its face worth, irrespective of commercial grale stations, would be estimated by the classer. "Climbers" and "sliders" are terms carried in the mind of the classer as he recognizes the variations, up) and lown, from any full, half or quarter grade. In typing, these exact variations stand as merits and demerits affecting an amalgamation or mixture forming a basic type. This basis of mixture is named by that simple process of mathcmatical calculation known as allegation. A type body is worth the sum of its component parts. That is all. This system of grading prevails only in large lot sales between lealer and lealer, and between dealers and manufacturers. The whole cotton crop is graded, first from the wagon of the producer by the single bale, or, as is most usually the case, in lots of from two to four bales. The classer buys mostly by 
the merit of the bale, or, in some instances, he may make a lump purchase. In either case he buys, as he should buy, safely. He grades by a strict commercial grading. With him. the first classer, barelys and fullys and climbers and sliders have no day.

All such margins are his legitimately if he has so graded. He may sell to a dealer, classing as he has bought, or he may possess the necessary means and business sagacity to type ont his purchases on highly improved grading. If he has represented a principal his purchases will surely take this course, and the second grading of this cotton will always be higher than the first. This reference is here made to the drop or descent of any commercial grade, because it applies in the descriptions of all other grades as will be noted.

\section{Strict Middling Fair.}

This is a half grade between Fair and Middling Fair. Its commercial description is the same as for Fair, except that the trace of impurities becomes a degree more pronounced. As these impurities bring it below the grade of Fair it must take its place in the next lower commercial grading If it should have higher merit, by reason of having just a small showing of impurities, such merit could receive credit only as it would give higher character to a type to be made up of slightly varying approximate grarles. A buyer in small lots buying on a basis of commercial grading, could make special types from his accumulation of purchases that would give to him the margin of profit between the commercial grade and the strict value above that grade.

\section{Middling Fair.}

This is the second full grade descending from liair. Its presentation of color is too slight to be called a shade, and still it is sufficiently distinct to mark a change. Its staple and gen- 
eral body must be as good as that of Fair, but it will carry a showing of the lighter and less injurious impurities easily observable. A slightly greater departure from white or an additional showing of impurities would type it Barely Middling Fair, but in commercial grading it wonlel descend to the thalf grade below.

\section{Strict Good Middling.}

This is a half grade between Middling liair and Good Middling. In its general appearance there may be seen a slight increase of shade, a small loss of staple character and a noticeable increase of non-injurious stains and light impurities. This grade is an improved Cood Middling, and is the highest point to which that grade can be taken, however free from impurities. Grade is first determined by staple and color, then cotton that is not fair can not be graded above Strict Good Micldling. It is not to be forgotten bowever, that grade first established on staple and color, may be materially affected hy condition. Strict Good Middling, Fully Good Middling, Good Middling and Barely Cood Middling are virtually the same except as to condition. Strict Good Middling, like other grades, may be typed on the next lowest quarter srade, but if comlition will not sustain a inll classing it would descend to the next Tower commercial grade.

\section{Good Middling.}

This is the third grade below lair. It has just been referred to as the basic type of a gromp of ascending and descending (puarter and half grades.

Good Middling does not mean a superior cast of Midllling: it means an independent type or srade better than Middling and differing materially from Niddling. The staple ranges from full seven-eighths of an inch to above a full inch in measure of length. Its color varies from the white of nearly Fair 
down through the wavings of white to a rich creamy cast, readily distinguished from the colurings known as tinges, and brighter in luster than the pallor-like whiteness belonging to the grade of Middling. Good Middling, bodied on its basic color and staple, will carry on its face and in its openings only a very small quantity of pepper-trash. a slight slowing of sheet trasli, a bare sprinkling of sleckheads, or perished eotton, a minimum showing of non-injurious stains and an occa sional fugitive mote or seed-end. I noticeable decrease of these impurities, with fair preparation (ginning) would type this grade a quarter higher to Fully Good Midding-a still greater disappearance and improvement would raise it to the grade of Strict Good Middling. As previously stated it could not be classed higher though every vestige of impurity shonld be removed. Any buyer or classer, however, would show his appreciation of so rare a type of cotton, and credit such cleanliness with its market worth. Again, if the color should be a shade deeper or the impurities a degree more marked the grade for typing would drop a quarter to Barely Good Middling, but as a single bale or in small lot sale it would be classed Strict Middling only. Added impurities might bring it to this grade as, in fact, it could by loadings be taken by degrees down throngh the several grades to Low Middling. It is to be olserved, however, that a Good Middling body, color and staple. in each grade that it may be reduced to by loadings, will admit of more impurities than would be allowed the same grades on their own respective natural bodies. That is, a Good Middling reduced by impurities to a Middling. would open to more trash, stain, etc., than would be allowable in a Mirldling proper.

\section{Strict Middling.}

This is the half grade between Good Middling and Middling. Strict Middling has been partially described uncler Good Midaling. but only as that grade reduced. Strict Middling proper 
is not so bright in color as Good Middling, but lighter than its basic grade, Middling. It will be mentioned again in the grades grouped around Middling. It is to be noted that Strict Middling bodied on Middling or on Good Middling, as it may be raised from the one or reduced to the other, would be allowed more or less impurities according as its color and staple approached the higher or lower grade. It has been claimed that the white of Strict Middling is a distinct grade color, but this play of mergings from both Middling below and Good Middling above would seem to annul such assumption. Strict Middling as an independent grade in body. color and impurity is to be treated as other grade, in typing and scaling down for grrade

\section{Middling.}

This grade is the basis of all cotton classification throughout the commercial world. (See Cotton (irader.) Its standard staple is from above three-fourths of an inch to one inch or more in length, and its defined color is a pale, clean, uniform white-not so bright as the higher grades, but yet a pure untinged white. In this central grade-color many minute degrees of variation are embraced, ascencling and descending each a half grade. These variations in ten thousand or more specimen types of Middling would show, probably, no two exactly the same, still the color quality of Middling would be manifest in each. Of course, this standard of color does not apply in case of reduced higher grades, as a Fair type could be brought to the grade of Middling through loadings. Middling is the representative type of the bulk of the American cotton crop. Its name implies the "most of the kind." as cotton is considered a kind of product. It is not the average grade, as supposed, but it is so called for the reasum that in point of body, color, and cleanliness it shows the character of the bulk of cotton gathered and prepared for the market. This being the case, it would seen that as no two seasons produce 
exactly the same Middling crop we should have no standarel Middling grade. But a standard has been established by averaging the output of varying seasons, and thougl this varying may sometimes be much above and at others much below the average, the standard is maintained.

With a good type of Middling in hand, after proving its body and color, observe clusely the quantity and the kind of loadings to be allowed. Particles of peppered trash will show here and there, not in quantity, but sufficient to be passed upon in grading, as "too much" or "allowable" as its quantity may measure. Witl a type to guide, it will be seen that a bare pronounced presence is all that is allowable. Sheet trash or larger parts of leaf trash, being less harmful, may show a little more boldly conspicuous. Sleekheads or immature staple and a little bad ginning are to be lookerl for: but if too much of the former is seen it would suggest a second and more careful examination of the body. Stains, just enough not to mar the white face of the type, may be passed over. An extra clean grade of Middling may be classed with Strict Micldling: likewise if the type is found below the standard it should be classed Strict Low Middling. Middling. in typing. will embrace these two grades, but under no circumstances will the smutty puff or blue tinge be carried in a white Middling type.

\section{Strict Low Middling.}

This is a half grade below Middling, and has just been partially described. In staple and color it is below Middling. It, of course, carries a larger quota of impurities. Often this grade is found comparatively clean, but on account of its body and color it can not be graded above Barely Middling. A small showing of smutty puff, blue tinge, or what is in some localities termed "smoky cotton," can be carried in this grade.

\section{Low Middling.}

This grade has a similar staple and body to that of Strict 
Low Middling, but with this grade the darker tinges, deeper stains and heavier impurities show their presence. It is an easy grade to place; its color and staple raising it above the ordinary grades, and its impurities dropping it to the lowest of the Mirdlling grades.

\section{Strict Good Ordinary.}

While this in classed as a half grate, it hav the independent characteristics of a full grate. It may sluw comparatively good staple and basic color as gond as Mildling. and yet by stains, trash and other impurities be graded down. It is generally a body of late pickings of good cotton stained by field exposure, mixed with the later immature openings that have been affected by frost. When little of the latter named mixture appears, and the type shows no blue tinge, and is otherwise fairly clean, classers sometimes place it in the grade of Middling Stained.

\section{Good Ordinary.}

This is, at present (season 1908-1909), the lowest commercial White Grade. It carries the darkest shade of white mingled with the full list of stains. It is only required that its staple shall be sound, by not being overloaded with decayed lower pod ends, known as sink stains, or by other indications of lamaged fiber. It embraces the former commercial grades below it, and is, therefore, now a lower type than it was formerly. But there is a limit to its loadings and after this limit is passed, "tailings" or "log-tails" is the assigned classification.

\section{Inferior Cotton.}

A surprisingly large percentage of the American cottun crop falls below the commercial grades. Many firms of buvers and single buyers deal only in these low grades. The largest profits are made and a season of storms or a late and bad har- 
vest means a bonanza of financial prosperity to them. The knowledge of the experienced cotton-classer is good capital in this field.

\section{Tinges and Stains.}

In recent classification we have only six grades of Tinged and one of stained. The tinges range from strict Gond Middling to Low Middling, including all half grades. Middling is the only grade of stained. It is a cleanly-gathered. well-ginned, neatly-prepared output of cotton that has been left ungathered too long after maturity. The stain is principally a burr and foliage weather mark. It will carry a greater degree of loadings than Middling white, though it is often found much rleaner.

In the lower grades of tinges luarmless stains are often allowed to such a degree that the grade would appear to be misnamed, but the character of tinge may be easily determined. The same quantity of stain on a white base would show a more pronounced character of color. The lightest tinge is (supposedly) seen in Strict Good Middling. Of course, no tinge could be classed higher. From this type the shades of tinge deepen by degrees to Low Middling. The parenthetic word (supposerlly) may be thus explained: A good bodied type of deep tinge nay be graded higher than a lighter type of poorer quality.

Any grade body of tinged or stained cotton will carry a greater degree of impurities than a similar grade body on a white base-a difference of about a half grade being allowed. For instance, a Strict Middling white, with its poorer body and allowed quota of impurities, if tinged, could be graded a Good Middling. This is done to compensate for the difference made in the market value of whites and tinges. Thus, Strict Middling white is worth one-quarter of a cent above the basis value-the same grade, tinged, though raised to the grade of Good Middling, would have the basis value only. 
This undervaluation is in part offset by overgrading. The system is wrong, but it is an established custom. Actual grades should not be cluangerl to regulate valuation.

\section{About Shipping.}

'This note is adlled, not in ridicule of the advertised work of a so-called cotton college, for the tricky notices it sends out to snare the unwary youth of the country are self-sufficient in the way of procuring amusement. It propuses to teach the boys how to buy and sell, and how to export. Noreover young men who learn to "export" are given "jobs" exporting." These notices bring to us indirectly many inguiries relative to the subject, hence, this general answer to all.

Cotton must be mored from warehomses, and whatever stups it may make or devious turns it may take, the factory is its ultimate destination. An American shipment of cotton to an American factury or to any other American destination would he termed a domestic shipment. American shipments to other countries are called fureign and are classed as exports.

All carriers by land or sea issue invoice receipts, bills of lading or manifests to shippers, showing the kind, the quantity, the condition and, in most instances, the value. of the goods received. These receipts are usnally issued in triplicate, one for the consignee, one for the shipper, and one to be retained loy the carrier.

An interior buyer may buy for bimself and ship to an "order to buy" from another, or he may buy for the order direct. He may biy and consign to a factor for selling. He may export through a factor, or he may export directly. The bankable valne of any cotton consignment exhibit depends upon the character of the shipment and the known commereial standing of the consignur and consignce. A domestic shipment of good character will usually command a bank advance of three-fourths of its stated value. 
The holder of a large lot of cotton, when he wishes to sell. gives notice to a line of buyers, making an exact descriptive exhibit of the types he may have. The best prospects are selected and actual types, usually a very small specimen sample of the different grades, are furnished. Upon this a deal may be closed. The same system applies to exporting. I manifest of the shipment is issued to be used by the shipper just as he would use a domestic bill of lading. the various lines of consignment, sale, etc., being virtually the same. Any well-stocked bookstore can furnish a directory uf every cotton buyer, both domestic and foreign. on the globe. From this list a shipper may select as he may choose for correspondents, filing with each his business address, his bank references and his field of purchase. A hook might be filled with unimportant details, as to forms of orders, commissions, advances. exchange, freight, insurance, ete., but there is but one important statement to be made and that is: "Establish yourself as a man (or firm) of business integrity, stand on a good commercial rating and prove yourself a safe buyer." After which all the other things will be added unto you, including exporting in its details.

It is easy to get a complete list of all responsible foreign buyers. (See Kelley's Directory.) 


\section{WARNING!}

Every page, every line, every word and every syllable comprising the contents of this little book, "The Cotton Grader, or frow to Classify cintum." is pretected by copyright. To a majority of thue into whose hands it may fall this anmencement will have no signficance. lint there are others. It is contemplated that the information it may consey shall go ont directly from its author w the individuals to be benefited thereby. This does not mean that any person desiring to possess a copy would be barred from obtaining it from the publishers or through the legitimate channels of trade. It means that any appropriation of the work, in parts or as a whole, to be used, secondarily, for the promotion of private educational enterprises would be an infringement. Let those concerned be governed accordingly.

N. J. MCARTHLR. 


\section{CHAPTER VI.}

\section{IN THE SPINNING ROOM OF A COTTON MILL.}

On a recent visit to the Georgia School of Technology the author desiring to follow the course of fiber from its introduction into the opening room to its form as finished yarn or thread, was referred by Prof. W. N. Randle, the efficient Director of the Textile Department, to one of his assistants, Prof. E. A. Camp, superintendtent of the spinning processes. Prof. Camp being informed that the especial object of the visit was to note the methods of cleaning and have him explain the general effects of Impurities, very courteously responded.

Many books with explanatory plates are to be had, defining all of this work, but such an illustration is not so satisfactorily edifying as to have an expert Supervisor go with you from machine to machine and explain as each was doing its successive part in the measure of completion.

The department is equipped with the latest improved machinery, and though as compared with large mill plants, it presents only a miniature appearance, nearly all can be seen in operation here that may be found in the large factories.

Prof. Camp was asked to write out in the same homely language of his explanations all that he had so courteously told. This he kindly agreed to do and complying, his written statement is herewith given, with the hope that it will prove instructive to those who may read it.

\section{Cotton Manufacturing.}

$$
\text { By Prof. E. A. Camp. }
$$

Cotton manufacturing comprises a great number of processes; and these vary, according to the product desired. so much that it will be impossible to give them to fit all cases. I therefore will mention only those most generally used. In 
the yarn mills (those which do not contain looms) the cotton passes through about as follows:

The ties and bagging being removed the cotton is mixed; contents of several bales placed together, so that there will be uniformity in staple and color. It is very necessary that there will be uniformity in staple (length) as it is impossible to set the drawing rolls of the machines to work different lengths of staple at the same time. If set for the long. many of the short fibers fall out as waste; and, if set for the short. the long ones will be broken and then fall out.

There are means provided for the adjustment or setting of these rolls in the various machines, but it is a rather difficult operation. Therefore when properly set, it is advisable to run about the same average length of staple, and not alter the settings. The eotton is taken from the mixing bin or room and passed through a machine to open it uthoroughly and feed it to the Lapper. The object of the Lapper is to separate the fibers, remove many of the impurities (in the form of dust, motes, leaf, stem, sand, etc.) and to get the cotton into a lap (or roll) that is uniform in weight per yard.

This lap is marle ly rolling up a sheet of cotton that is from forty to forty-five inches in width and about fifty yards long. The weight per yard varies from about eight to sixteen ozs. depending upon the product into which it is to be converted.

There are minally three lapping processes nsed, viz: breaker, intermediate, and finisher. Often thongh, the intermediate is omitted on the better stapled cortons.

(n) leaving the finished Lapper (or Picker, as termed in some localities), the cotton is taken wh the Revolving Top Flat Card. This carding neratin removes imptrities, neps, motes, short fibers, etc., left ly Lappers, combs or cards the fibers, and converts the cotton into a sliver (rope form). Six card slivers are placed at the back of the first drawing frame. and passed throngh, side by side, converging at the front of 
the machine into one strand or Sliver. The weight per yard of the latter is about equal to the weight of a single strand at the back of a machine; or as received from the card. This reduction in weight is accomplished by Roller Drafting. i. e., having the successive lines of rollers through which the cotton passes accelerated in speed.

The abnve drafting or drawing out tends to lay the fibers parallel. Another rery important object of this machine is to get a Sliver which is uniform; this being accomplisher $\therefore$ the doubling of six at the hack of the machine.

There are usually two processes of drawing used; the second being further to accomplish objects sought for in first process.

The Sliver is now passed through the Shbber, the objects of which are further to attentuate, to insert a small amount of twist, and to wind on bobbin the small strand of roving or slubbing. The drafting on this and succeeding machines is for the purpose of reducing the weight per yard and not for getting the fibers more parallel. The slubbing is fed doubly to the intermediate Fly Frame, which is the next process. The objects for this machine are the same as for previous machines. Of eourse the doubling here tends to make more even or uniform work.

The internsediate roving is fed clouble to the fine frame, the objects of which are the same as those for the two preceding machines.

The roving has now been drawn down sufficiently fine so that the balance of drafting necessary to give the required number for yarns can be obtained on Spinning Frame. The twist imparted here is very hard as compared to that of the slubber intermediate and fine frame; the latter being only sufficient to give strength enough to enable it to be unwound on next machine.

The yarn is spun with different amounts of twist, depend- 
ing upon its future use. Warp yarns requiring more twist than Filling and Filling, more than Hosiery yarns.

The number of the yarn is the number of hanks, of 840 yards each in one pound.

The processes given above are generally used for medium numbers, but for coarse numbers, the Fine Roving Frame is usually omitted, and the roving carried direct to spinning frame from the Intermediate Fly Frame. This roving is often fed singly into the Spinning Frame. For the higher numbers the Jack Frame is used. This machine follows the Fine Roving Frame and of course preceles the spinning trane. Combed yarns and all fine numbers pass through the machines already given, and sometimes others. These yarns are made from medium to long staple cotton. To make a superior yarn it is necessary that the Fibers be of Equal Length, and this condition cannot be obtained by carding alone; therefore the Comber, which takes out, as waste, all fibers below a certain length, all impurities, and gets the remaining fibers parallel. las to be resorted to. The card slivers are passed through the Sliver Lap machine with fourteen doublings and a low draft, ancl are made into a small narrow lap. These laps are fed into the Ribbon Lapper, whose objects are the same as the drawing frame, lut working Laps instead of Slivers. The cotton in the form of small narrow laps is next passed through the Comber. The combed slivers are passed through the drawing frane (six (foublings) from draw frame to Slubber and so on as previously given. In working the better staple cotton wsually there are only two lapping processes used; omitting the intermediate machine.

The filling yarns are taken from the spinning frame direct to the looms to le placed into the shuttle, but the warp has several other processes through which it has to go. The warp yarn is spouled, i. e.. contents of several spinning bohbins are placed (womnd) on a large spool. These spools have the yarn 
withdrawn or unwound from them and rewound on to a large beam, holding 400 pounds or more. This machine is known as a Warper or Beamer. Several of the above beams are unwound and the yarn passerl through a Slasher or Sizing machine. The starcin or size tends to glue the fibers composing the yarn lugether so that the yarn will not chafe in weaving. The yarn is wound on to a small or Loom Beam at the fromt of the slasher. After the threads have been drawn through the harness and reeded the beam is ready to be carried to the loom.

Many milis take the yarn from spools to the Twisting (doubling) machine, where two or more threads are twisted together. From the twister the yarn is carried to the conewinder reel. etc., depending on its future use. 


\section{CHAPTER VII.}

\section{A FRIENDLY CRITICISM.}

The latest issue of a work on Cotton emanates from Mr. T. S. Miller, Sr., a Texas author. The title of his work is "The American Cotton System." It is an excellent arrangement of the quoted opinions of more than al half dozen eminently prominent Americans, inclurling congressmen, exchange officials, and large firms of cotton dealess, combined with a neat and accurate compilation of matter from a full dozen written anthorities upon the subject. Notwithstanding this array of Quotings, there is sufficient presentation of the athor's indiviluality to stamp the work "original."

It contains much useful information not to be found in any one previously published work. Mr. Miller devotes a long chapter to the suliject of Cotton Classification, hence this notice. Ile names and gives the (market price), grade differences of the eighteen current commercial srades, and in the same line of parasraphs asserts that there can be no standard type, nor as he terms it, "mechanical measurement," by which one of these gradings may be distinguished from another, especially those bearing near semblance of feature. A Standard Type is a Mechanical Measurement, a Guide whether imprinted on the menury of an experienced classer or given for comparison inte the hands of the less expert novitiate. In the name of reason, if not from the study of original Standard Types or Mechanical Measurements, where, wh where, did the gifted expert receive his knowledge of classing? The fact that classers sometimes differ from each other, and thist a classer not infrequently differs in a secumbl wallum from his first, is no argument that Standard Types or Mechanical Measurements do not form the basis of all cotton classification. Let us take a sample of the Grade Good Middling. The face shows it to he a standard type, and without further exam- 
ination, novice and expert alike would so grade it. But there is to be a further eaxmination. It upens to increased loadings of trash, and besides stains and cut fiber are presented to view. The expert classer rates it Strict Middling, and the beginner, of any common sense, would not do otherwise. Again a similar sample of the same Standard Type, Good Middling, shows on its openings to be so clean and well prepared that both alike rate it. Strict Good Middling. Bon are Good Middling Types on Grade but they have been rated, one lower and the other hiwher than that standard. This Rating is the great mysterins: "husaboo" that has placed cotton classing in the category of inspired work. The highest Standard Type of animal life graded in the lines of creation is Man. All of this Type are not alike. We have cripples, blind men, deaf men, and men both Inferior and Superior. They are all graded "Man," but are to be Rated according to their several degrees of yifts or infirmities. No one would make the mistake to Grade a man as some other type of animal, though his rating might scale him down to the commercial worth of a monkey. Neither would any one having even a half familiar acquaintance with cotton make the mistake to place any sample exhibit elsewhere than in line with its Standard Type of Mechanical Measurement. If upenings showed it to be higher or lower, he would so Rate it.. The baseless, absurd opinion that cotton classing cannot be learned and be as well known to any man of ordinary intelligence within a very short period of tine, as it may be known to any other man. is an inheritance bequeathed to believing. minvestigating producers who have all along accepted this "Pumpkin and Rock" doctrine and method of doing business as their whole ancestra! lines for generations before them have accepted it. Not many dollars of cotton money except that paid the producers (Suuthern cotton mills operated on Eastern capital not excepted) remain in the section of country where it is produced. This fact should be an appealing argument influencing every resi- 
dent of that section to feel an interest in common with the producer. Millions upon millions of dollars have been lost to the farmer as a consequence of his ignorance of grading and these millions have been indirectly a loss to all the people of his section. It is a deplorable truth that all this loss has followed upon the unfounded remark made far back in the past, that a farmer did not have common sense enough to grade his cotton. This remark grew into a popular belief, till now its force is accepted by the majority as an existing law of mental misendowment not to be changed. The producer has paid high for the luxurious enjoyment of an ancient custom, and it is to be regretted that Mr. Niller, who has given to the public an otherwise excellent work, has omitted the investigation of this great error. There are but two parties to the transaction embracing a transfer of property right in cotton. One of these is the producer, whose knowledge of cotton should be superior to that of any other man, and the second party is the buyer, many of whom would not know a stalk of cotton as distinguished from an Okra bush, if such knowledge should be based on familiar acquaintance with the two productions. Yet the Wand of Custom has been waved over the buyer, and he enters the ficld, knowing all about the grades of cotton. He is versed in all the signs, winks, grips an:l pass-words of the Profession, and though, perhaps, only a beginner, it is his secret. The farmer, however, sits veiled in the mysticisms. He wonders in this progressive age, while he considers the many fallacies, false beliefs, and harmful, ignorant practices of his forefathers, why the higher native intelligence possessed by them did not reveal these mistakes. As he does this he swallows his "dope" with a smile of complacency, and accepts as truth a statement which would have been discarded as unreasonable by any of the most ardent believers in New England witcheraft.

It would we well if the organized bodies of farmers in the cotton section would combine with their plannings to hold 
for higher prices, and to seek the best points of market some slight knowledge of What It Is They Have to Sell. County Institutes should be established throughout the territory to be presided over by intelligent growers, in which Cotton Grading should be made a study through a system of "Standard Types," and "Mechanical Measurements." Why not mix a little of this study with the items on the farmers' meeting programs? It would bring remunerative returns without question. A point has been raised that such knowledge would be of no benefit to the farmer, that the grading bnyer would purchase on his own grading only. This is equal to the cry of "Surrender" before there has been a declaration of war. This law might stand where only one of many was affected. But let it be known to all that every cotton producer has a fairly good knowledge of cotton classing and the arbitrary law of the buyer would stand self-abolished. It is strange that in the conservation of mental energies the farmer should begin the practice of economy of thought just at this point, by treating this item of knowledge as a matter only intellectually cumbersome. It is not only strange but shameful; and if the system is to be continued, the several cotton states, having the right to protect the common interests of the whole people wihin their borders, should enact cotton classing laws, operative in the same way as those applying to weights and measures. I have stated in other writings (explaining that I intended no reflection on my people of the South) that if cotton were produced in Connecticut or Massachusetts it would not be easy to find a male member of the population of those states above the age of fourteen years who would not understand thoroughly the system of cotton classing. Its study would be made a part of the common school curriculum, and though every old expert cotton classer, every interested cotton buyer and every manufacturer on the globe, should go as a lobby before their legislative bodies, arguing that cotton classing could not be taught through Standard Types 
and Mechanical Measurements, they would not be heard above the reasoning of common sense, and the laws would be enacted. I am making this criticism (and excellent advertisement) of Mr. Miller's book, a part of this publication, not because there is ample room between its covers to give it a place, but because it is proper matter to be included. The work is written to be used primarily as a text book in our common schools, but an effort will be made to give it a large and general circulation otherwise.

\section{With Heavy Accent on the "I."}

Unfortunately for one seeking information on the subject of cotton classing as a study, he naturally approaches a known cotton classer. When he asks whether or not cotton classing can be tanght snccessfully in any of the schools now conducted for that purpose, he is langhed to ridicule, and told that the idea is absurd; that cotton classing is not to be learned at all, that it is just known, "felt in the bones," after many years practical work handling it. ()f course, the applicant for information leaves disconraged. If he had plied him with a few pertinent questions tonching his career as a classer. the answers given wonld not have snstained the declarations that had killed his ambitions to become one of the guild. Why men of high reputation for truth and general honesty will make these (untrue) stereotyped answers is a mystery almost as great as the fact that they are belived by all the outside world. Each and every one will leave the inpression that he, himself, is master of the art, however short the time it has taken him to attain such proficiency. The answers invariably name a period just a little short of the time each has been in active work.

Let ns quiz a few of them, and note their respective declarations.

Mr. A., as an expert cotton classer will you tell me what 
length of time is required to gain a knowledge of your profession?

Ans. "I have been engaged in the work about twenty years, and I should say that it is only within the last year or two that I could claim to be what you might call, pretty well 11p."

Q. How did you gain your first knowledge of the work?

Ans. 'Oh. I just picked it up' watching good graders, now and then, and noticing the names they gave to the different samples?"

Q. Did you begin buying on the knowledge you had thus acquired?

Ans. "Oh, yes: but I had good friends whom I could sometimes consult."

Q. Did you make any mistakes in your early work: that is. during your first and second seasons as a classing buyer?

Ans. No, not one, but I was very particular.

Let like questions be propounded to B. C. D. and E, who have worked at this business respectively fifteen, twelve, ten and five years and the answers from each will be in substance that of $A$. except for the last question, when each answers the same. "No. not one, but I was very particular."

Let us next present D, who is like the others a "pick it up" graduate, but who is just entering his third season as buyer. He wil ltell you that two years of experience are reguisite, but to the last question he will join the others in the speech. "No, not one, but I was very particular."

In concluding this notice I will say again that Mr. Miller makes a mistake in promulgating through his publication this "strain of false sonnet."

For several generations there has been no one in position to contradict the declarations behind this grand scheme of :nterested cotton manipulators, but now it is different. Thnusands are going ont from the various cotton schools of the country, who know cotton and who gained that knowledge from a study of "Standard Types" and "Mechanical Measurements." 

One copy del. to Cat. Div. 
